\title{
Conceptualizing micro-adaptive teaching practices in content-specific ways: Case study on fractions
}

\author{
Susanne Prediger ${ }^{1,2^{*}}$ (D) $\cdot$ Kim Quabeck ${ }^{1} \cdot$ Kirstin Erath $^{3}$ (C) \\ ${ }^{1}$ TU Dortmund University, Dortmund, Germany \\ 2IPN Leibniz Institute for Science and Education Research, Berlin/Kiel, Germany \\ 3Martin Luther University Halle-Wittenberg, Halle, Germany \\ ${ }^{*}$ Correspondence: prediger@math.tu-dortmund.de
}

Received: 18 April 2021 | Revised: 28 January 2022 | Accepted: 3 February 2022 | Published Online: 8 February 2022

(C) The Author(s) 2022

\begin{abstract}
Adaptive teaching on the micro-level of teacher-student interaction has often been investigated, but rarely with respect to students' content-specific learning pathways. In this paper, we present an analytic approach to disentangle the learning content into its components and to capture the content-specific adaptivity in teaching practices with respect to teachers' student focus and goal focus. For this, adaptive teaching is conceptualized as teachers' targeted steering trajectories navigating from students' initial ideas towards the content goals. In a case study with video data from 19 middle school small-group sessions on comparing fractions in context problems, we show how the adaptivity of the teaching practices can differ with respect to student focus and goal focus even when the same teacher moves are used. This calls for extending professional development programs that combine working on teacher moves with unpacking content goals.
\end{abstract}

Keywords: Adaptive Teaching Practices, Content-Specific Navigation, Fraction Comparison, Mathematics Classroom Interaction

How to Cite: Prediger, S., Quabeck, K., \& Erath, K. (2022). Conceptualizing micro-adaptive teaching practices in content-specific ways: Case study on fractions. Journal on Mathematics Education, 13(1), 1-30. https://doi.org/10.22342/jme.v13i1.pp1-30

Adaptive teaching can be defined as 'teachers' adjustments to students' individual developmental states $\ldots$ and ... to students' individual differences and learning needs" (Hardy et al., 2019, p. 169/171). This general idea of characterizing adaptivity by a strong student focus dates back to Roman and Chinese writers more than 2,000 years ago (Corno, 2008) and is widely considered a core element of effective teaching (Parsons et al., 2018; Hattie, 2009). Based on this consensus, contemporary researchers in cognition and instruction have continued to work on conceptualizing and investigating how teachers' adjustments look and which of them can leverage students' learning, with a focus on topic-specific learning goals.

Multiple studies have disentangled micro-adaptive teaching practices with respect to typical teacher actions, stimuli, and backgrounds that lead to teachers reacting in specific ways (Parsons et al., 2018). Within these studies, the addressed student aptitudes have comprised self-regulation (Corno, 2008), cognitive complexity (Nathan \& Kim, 2009), and language proficiency (van de Pol et al., 2010), and different kinds of micro-adaptations have been investigated for each of these aptitudes. 
In contrast, micro-adaptivity to "students' individual developmental states" (Hardy et al., 2019, p. 169) has rarely been investigated in a content-specific way, which means by focusing students' development on their individual learning pathway towards the intended mathematical learning goal. In order to close this research gap, we investigate the adaptivity of teaching practices with respect to the content learning pathways, asking two research questions: What teaching practices do teachers use for working with students' ideas and strategies and for bringing them to the content goals? How can the teaching practices be characterized with respect to their degree of micro-adaptivity?

To pursue these research questions, we conceptualize adaptive teaching practices as fine-tuned content-related interactional adjustments on a micro-level and analyze video data from 19 small-group sessions working with seventh graders on comparing fractions in a context situation. The first section presents the theoretical background on adaptivity, teaching practices, and the content in view, leading into a suggested conceptualization of micro-adaptive teaching practice. The second section introduces the methodological framework of the qualitative video study, and the third section the identified practices.

\section{INTRODUCTION TO THE THEORETICAL BACKGROUND}

Corno and Snow's (1986) seminal paper on adaptivity is widely cited for the distinction of macroadaptivity in the longer-term lesson planning and micro-adaptivity in the short-term classroom interaction in situ. Although our focus is on micro-adaptivity, we start by summarizing the research on macroadaptivity, for which the content focus has been much better established. This will help to articulate the research gap.

\section{Macro-Adaptive Teaching: Differentiation and Carefully Planned Content Trajectories}

The research on macro-adaptive teaching has mainly followed at least three lines:

1. In general education research, many researchers have emphasized the heterogeneity of students' developmental states and aptitudes and focused on practices of differentiated instruction (see Hardy et al., 2019, for an overview). In this context, learning opportunities have been designed or studied with respect to their potential to address diverse learning needs, but they have not necessarily been matched individually to specific areas of content (e.g., Lawrence-Brown, 2004).

2. In mathematics and science education research, adapting to students' developmental states has been interpreted as related to the specification of hypothetical content trajectories: Content trajectories (also called hypothetical learning trajectories or learning progressions, Siemon et al., 2017; Clements \& Sarama, 2004) are based on empirically grounded local instruction theories and hypothesize typical steps in which a certain subject matter content can be taught and learned. In many strategies, the content trajectory starts from students' intuitive resources (ideas, conceptions, and strategies) and then leverages them into more regular concepts and strategies of the scientific discipline. Designers and teachers can plan learning opportunities, tasks, and support means according to these hypothesized developmental steps and adjust the planning to their students (Simon, 1995). Even if the steps in the content trajectories cannot completely capture the complexities of students' real learning pathways (Confrey, 2006), the specification of content trajectories proved to be a very useful content-specific approach for planning macro-adaptive teaching, in classical curriculum materials or adaptive digital learning systems (Siemon et al., 2017). 
3. In (second) language education research and language-related research in mathematics education, macro-adaptive teaching has mainly been designed and studied under the term macroscaffolding, especially for students with limited academic language proficiency (Gibbons, 2002; Prediger \& Pöhler, 2015). Similar to content trajectories in mathematics and science, macroscaffolding plans with language trajectories sequenced from students' informal everyday language resources via more structured academic language until reaching the technical language (Gibbons, 2002; Adler, 2001).

For mathematics, science, and language learning, the success of macro-adaptations has been shown to depend on the appropriateness of pushing each students' learning along this content or language trajectories towards the learning goal (Siemon et al., 2017; Confrey, 2006; Prediger \& Pöhler, 2015). If the steps are not sufficiently adjusted to students' developmental states, the learning pathways do not reach the goals. So, in macro-adaptive subject matter education strategies, the focus on students' developmental state (here called student focus) is combined with a focus on reaching the learning goal (here called goal focus).

\section{Micro-Adaptive Teaching Practices: Conceptualizations and Empirical Findings}

Lim et al. (2020) emphasized "there is much potential for enhancing mathematics instruction by learning more about how teachers listen to and build on students' responses" (p. 377).

Two insightful research reviews have summarized the current state of research on micro-adaptive teaching and its varying conceptualizations (Parsons et al., 2018; Gallagher et al., 2020). The multiple conceptualizations have been found to overlap in the core of defining micro-adaptive teaching "as a teacher response to stimuli focused on supporting student needs" (Gallagher et al., 2020, p. 2), with an emphasis on supporting student needs. Some characterizations have also included the teacher deviating from their original plans; we and other researchers do not include this deviation as a necessary criterion but as an appropriate match to students' needs.

Parsons et al. (2018) summarized the research findings of 64 research studies across different subjects. The studies identified typical teacher moves that can be subsumed under the categories of questioning, encouraging, managing, giving feedback, making connections, assessing, modeling, explaining, and challenging. The studies also contributed to understanding typical stimuli in the teacherstudent interaction (e.g., specific student behavior) and the backgrounds to why teachers chose their moves (e.g., persistent teacher factors, affordances, and barriers, but also teachers' reflection and metacognition). In addition, Schwarz et al. (2021) showed in their analysis of sense-making moments that the same moves can be applied for different teaching practices, for instance, for expanding, maintaining, or shutting down students' sense-making processes.

As we will show in this paper, the moves collected as common typologies of responses from Parsons et al. (2018) need to be complemented and sometimes unfolded to investigate their role in microadaptive teaching practices with a focus on students' content-specific learning pathways (see Section 2.3; moves from Table 1 are marked by -...-). For instance, the move "questioning" can have two different functions: As an initiation move, it intends to -elicit- students' thinking (Munson, 2019; Jacobs \& Empson, 2016), whereas as a follow-up move, it intends to -elaborate- on students thinking regarding the depth of students' understanding or the connection to other concepts (Munson, 2019; Smith \& Stein, 2018; Schwarz et al., 2021). The latter can also be part of the "challenging" move depending on the actual phrasing of the question. An example of a move that needs to be complemented compared to Parsons 
et al.'s (2018) list is -initiate student repair-: This follow-up move is related to "assessing" and "giving feedback" but goes beyond pure evaluation as it activates students to reflect and repair their partially incorrect strategies (Buttlar, 2019).

In the large body of research on adaptivity, different dimensions of students' aptitude were addressed, spanning from students' general intellectual abilities (including intellectual impairments) and personality characteristics (such as affective-emotional dispositions) and cognitive styles (all already mentioned by Corno \& Snow, 1986). Many researchers have investigated micro-adaptivity with respect to the language dimension, for which teachers' micro-adaptive practices have been mainly investigated as micro-scaffolding students' language production (van de Pol et al., 2010). Corno (2008) discussed micro-adaptive practices mainly with respect to open or strongly structured teacher prompts, so the underlying dimension of aptitude is students' self-regulation. Nathan and Kim (2009) demonstrated in a case study how a teacher adjusts the complexity of his elicitations according to the quality of students' answers (without calling it micro-adaptivity), from eliciting yes/no responses over explaining to justifying. Jacobs and Empson (2016) presented teachers' adaptive practices when supporting students' modeling processes for story problems, so the dimension is students' developmental state in the modeling cycle and the progressive schematization. These examples show that the repertoire of teachers' micro-adaptive practices depends heavily on the dimension of aptitude in view, even if the research reviews by Parsons et al. (2018) and Gallagher et al. (2020) made the considered dimensions of aptitude only occasionally explicit.

What seems to be missing in most of the literature on micro-adaptivity is the dimension of content trajectories: Although often discussed with respect to macro-adaptivity (see previous section), most studies on teaching practices on the micro-level have seemed to abstract themselves from the content in view. Although Jacobs and Empson (2016) as well as Prediger and Pöhler (2015) pleaded for taking content trajectories explicitly into consideration when investigating micro-adaptivity, Gallagher et al.'s (2020) research review on 23 studies on micro-adaptive teaching in mathematics education identified only three studies that briefly mention teachers' reflections about the content trajectory or the content goals. Chazan and Ball (1999) had already emphasized in their seminal paper "Beyond Being Told Not to Tell" that a teacher's student focus needs to be enhanced by a clear orientation towards the learning goals while guiding discussions. One exception is Huang and $\mathrm{Li}$ (2012), who compared experts and novices and find that expert teachers monitor students' progress along a planned content trajectory and take actions to initiate a push forward much more than novice teachers.

In total, we conclude that the current research on micro-adaptivity has multiple ways to operationalize the adaptive student focus. We conclude that more content-specific research is required on teachers' micro-adaptive practices with respect to both student focus and goal focus. This paper presents a study in which the mathematical content goal in view is comparing fractions in a context situation.

\section{Mathematical Content in View: Comparing Fractions in Contexts}

The content-specific analysis of micro-adaptive teaching practices requires a thorough unpacking of the content in view, here comparing fractions.

Students' difficulties with conceptual understanding of fractions have often been documented (e.g., Behr et al., 1992; Aksu, 1997), so it is a suitable topic for analyzing teacher-student interaction. For the specific topic of comparing fractions, students' adequate or non-adequate strategies have been empirically documented in various studies (Behr et al., 1984; Clarke \& Roche, 2009), with the following six occurring most often: 


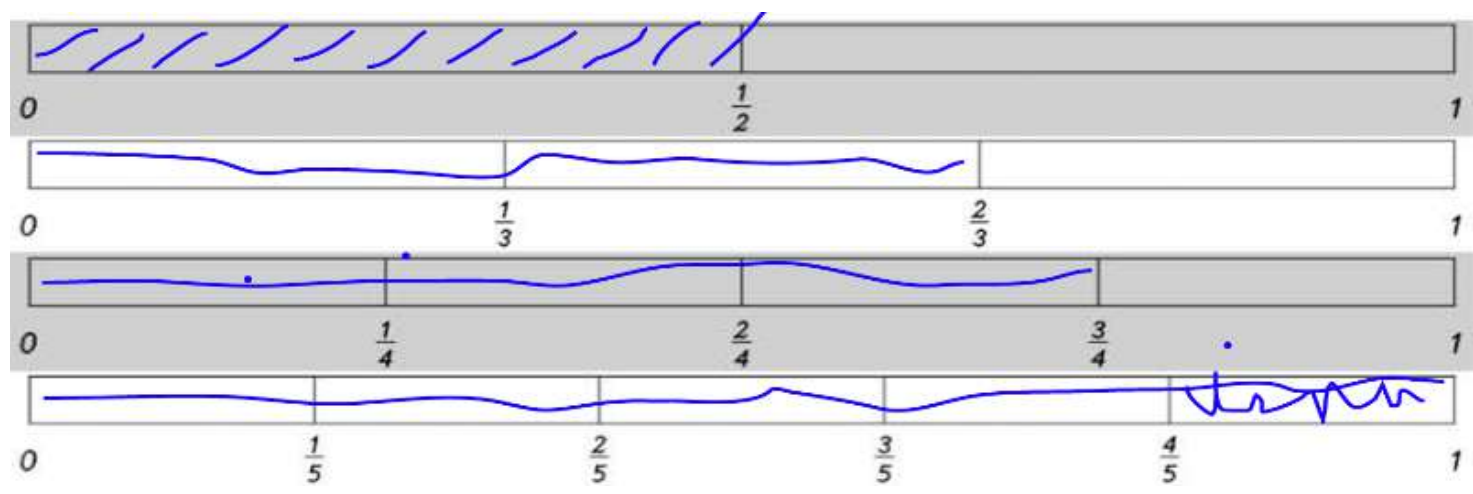

Figure 1. Comparing $1 / 2,2 / 3,3 / 4$, and $4 / 5$ in the fraction bar board

- Translating to a manipulative/graphical representation and compare the shares visually

- Considering only the numerator (correct if the denominators are equal)

- Considering only the denominator (correct if the numerators are equal and if smaller denominators are identified with larger fractions)

- Comparing by a benchmark (e.g., smaller/larger than $1 / 2$ )

- Gap thinking (e.g., 5/6 and 7/8 are equivalent because both miss one piece; incorrect)

- Residual thinking (e.g., 5/6 is smaller than 7/8 because the remainder in sixths is bigger; correct)

- Converting to the same denominator and then considering only the numerator (standard procedure)

In the teaching learning arrangement of our study (Prediger \& Wessel, 2013), the comparison of fractions was introduced on the fraction bar board in order to strengthen the first strategy and the conceptual underpinning of the other strategies (Clarke \& Roche, 2009). Within the graphical representation of the fraction bar board, other strategies were also discussed (see Figure 1).

After introducing the comparison of fractions on the bar board, a later task presents a context problem of a soccer competition in which equivalent scores for different numbers of attempts are to be compared in order to reinvent the concept of equivalence of fractions (see Figure 2).

When the hits are considered relative to the attempts, fractions can be used for mathematizing, for instance, using the graphical solution strategy in the fraction bar. But students also structure the context situations using other context-bound strategies (Quabeck \& Erath, 2020), as Figure 2 summarizes. Some students use static comparisons, others more dynamic transformation strategies. The anticipated content trajectory

- starts from non-adequate strategies focusing only one part (number of attempts or number of hits),

- goes via partially adequate strategies that coordinate attempts and hits by structuring the situation additively, and

- aims at (nearly) adequate strategies that coordinate attempts and hits by structuring the situation multiplicatively.

From a mathematical point of view, these informal, context-bound strategies correspond to well-documented strategies for comparing symbolic fractions (noted in brackets in Figure 2). However, from the point of view of students who do not yet structure the situations using fractions, they are not necessarily related. It is then the teachers' task to connect them in the steering trajectory and push students' thinking forward along the content trajectory. 


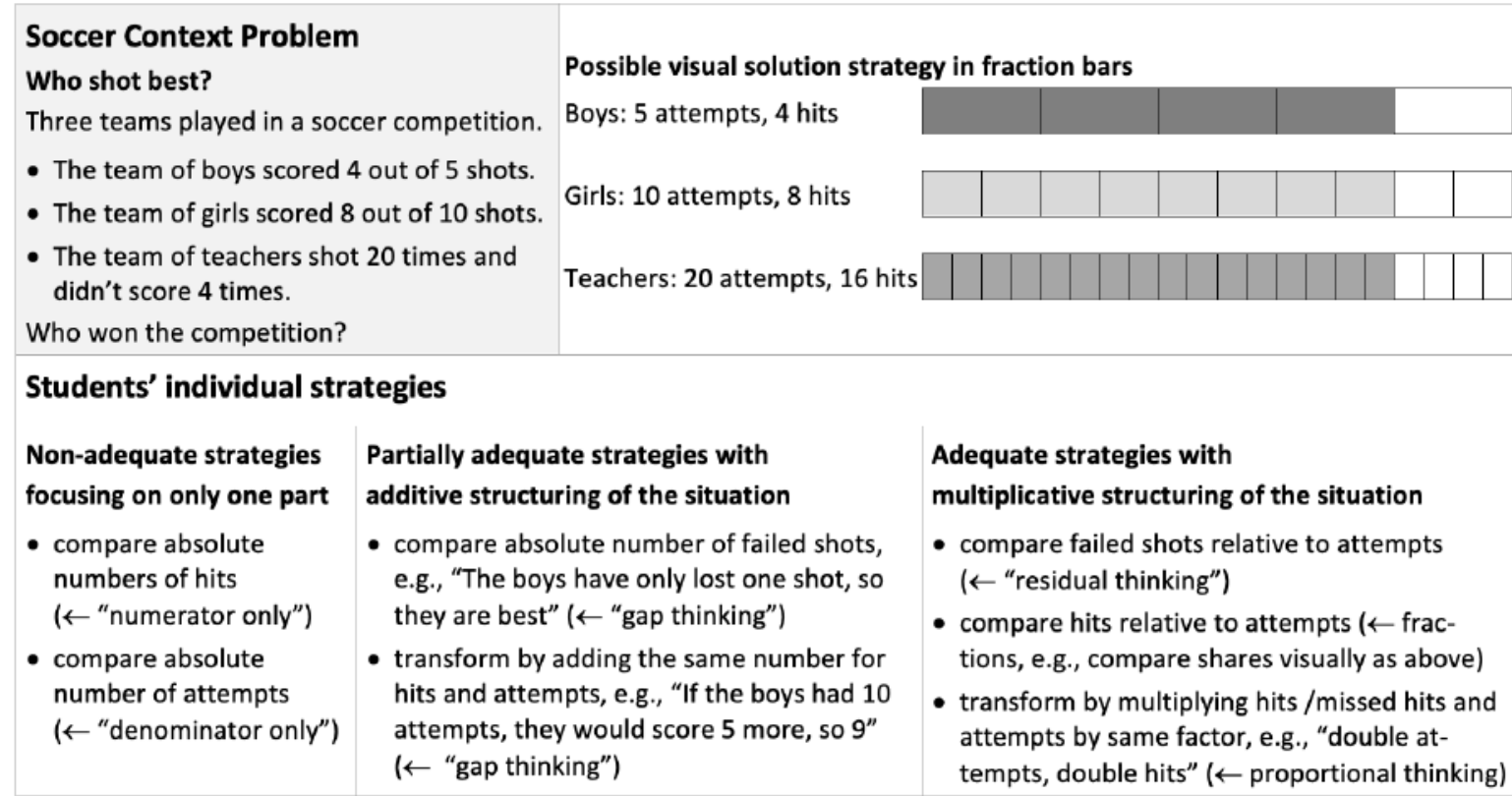

Figure 2. Soccer context problem and typical solution strategies

In our study, the Soccer Context Problem was used after fraction comparison had already been introduced (in context of sharing). Based on some knowledge on fraction comparison, the Soccer Context Problem allows students to gain conceptual insights into why multiplicative structuring of situations and mathematizations by parts of a whole can be more suitable than additive structuring in contexts other than sharing and also requires connecting non-adequate and target strategies with the underlying structuring (as argued also by Loibl \& Leuders, 2019).

Teacher-student interaction while working on the context problem aims at engaging students in active processes of structuring the context situation and of comparing the scores using different strategies. The teaching can count as adaptive when it picks up students' ideas and leverages them towards the intended multiplicative structuring while maintaining students' agency and cognitive demand. But how can the adaptivity of teachers' navigation within the landscape of possible strategies on the micro-level be characterized?

In the empirical part of this paper, we will show that adaptivity cannot be characterized only by categorizing teacher moves in a content-independent way because this would not help to capture how the teacher navigates on the content trajectory. We will further show that the trajectory is not unidimensional. Instead, different steering trajectories are possible across a two-dimensional content-specific navigation space (Figure 3). On the horizontal axis of the content-specific navigation space, we locate students' strategies according to the reference objects the students and teachers refer to (from isolated structuring with "absolute hits" to the targeted multiplicative structuring with "hits relative to attempts"). On the vertical axis of the content-specific navigation space, we locate whether the interaction is about the targeted "dynamic transformation of fractions into equivalent fraction" (ideally by refining the fraction bars into finer pieces or by doubling the hits and attempts) or still in a stage of "static comparisons" or "no comparison" (e.g., while only describing one situation). 


\begin{tabular}{|c|c|c|c|c|c|c|}
\hline $\begin{array}{l}\text { Reference object } \\
\text { (focus) }\end{array}$ & & $\begin{array}{l}\text { Absolute } \\
\text { hits }\end{array}$ & $\begin{array}{l}\text { Absolute } \\
\text { attempts }\end{array}$ & $\begin{array}{l}\text { Absolute } \\
\text { missed hits }\end{array}$ & $\begin{array}{l}\text { Missed hits } \\
\text { relative to attempts }\end{array}$ & $\begin{array}{l}\text { Hits relative } \\
\text { to attempts }\end{array}$ \\
\hline & $\begin{array}{l}\text { Starting } \\
\text { point }\end{array}$ & & & & & \\
\hline \multicolumn{7}{|l|}{ No comparison } \\
\hline \multicolumn{7}{|l|}{ Static comparison } \\
\hline \multicolumn{7}{|l|}{ Indirect transformation } \\
\hline \multicolumn{7}{|l|}{ Additive transformation } \\
\hline Dynamic transformation & & & & & & \\
\hline
\end{tabular}

Figure 3. Content-specific navigation space for developing comparisons of fractions in the soccer context

In the content-specific navigation space, the overall content goal is located in the bottom right field. The other categories are ordered so that the mathematical sophistication increases the further down and the more to the right the field is located in the content-specific navigation space. Thus, the anticipated content trajectory also moves from the left to the right and from the top to the bottom. For example, the two columns on the right contain all nearly adequate strategies such as residual thinking ("missed hits relative to attempts") and fractions ("hits relative to attempts") from Figure 2. But students referring to "hits relative to attempts" might not automatically also refer to "dynamic transformation" as proportional thinkers do. Thus, this example shows how the second axis of the content-specific navigation space provides a differentiation that allows tracing of the teachers' and students' pathways in the conversation.

In addition, the existing research (on comparing fractions in a context situation) points to a third axis that needs to be considered: Each strategy (in a field of the content-specific navigation space) can appear in representations that are contextual, graphical, or symbolic. For example, the adequate strategy that addresses "hits relative to attempts" with a "dynamic transformation" can be addressed by referring to the fraction bars as indicated in Figure 2, by referring to the context ("It's a draw because if you shoot two times more you also need two times more hits"), or by referring to the symbolic representation (4/5 equals $8 / 10$ because 4 times 2 is 8 and 5 times 2 is 10). Hence, information on the representation that students address in their utterances is a third integral part of the analysis.

Altogether, the carefully unpacked learning content represented in the content-specific navigation space is a tool crucial to mapping students' strategies and the teachers' work with them. In order to investigate micro-adaptivity, the content-specific navigation space then serves to investigate how teachers use students' strategies of varying sophistication in both axes and the representations to proceed to the content goal and create sense-making moments with students' context-bound strategies.

\section{Suggested Conceptualization of Content-Specific Micro-Adaptive Teaching Practices}

Above, we identified a lack of reference to the subject matter content in view in existing conceptualizations of micro-adaptive teaching as the research gap we intend to tackle. To close this research gap, we conceptualize micro-adaptive teaching practices as the teachers' steering trajectories on a contentspecific navigation space (specified in Figure 3 for our case).

Methodologically, this conceptualization of teaching practices resonates with the methodological choice of Schwarz et al. (2021) to take a medium grain size for the unit of analysis, as the single teacher move or triplet of turns in an IRE sequence is useful for understanding student thinking, but not for capturing teachers' steering activities. In their study on primary science teaching, they acknowledged that research on isolated teacher moves was insightful, but they demonstrated the potential of analyzing the 
medium grain size of sense-making moments to see how teachers can expand, maintain, or shut down students' opportunities for sense-making along several utterances. In line with Schwarz et al. (2021), we capture teaching practices in this medium-size unit of analysis of sense-making moments rather than more isolated teacher moves as have often been identified in the existing research on micro-adaptivity (Parsons et al., 2018; Gallagher et al., 2020). Teaching practices for sense-making moments can be combined into larger teaching practices in sense-making episodes (as, e.g., investigated by Prediger \& Erath, 2014).

On this basis, micro-adaptive teaching practices are conceptualized here as recurrent patterns of teachers' steering trajectories that maintain a strong student focus and a strong goal focus at the same time. This means that we define micro-adaptivity by the degree to which teachers work with students' initial ideas and shift their learning pathways towards the targeted content goals:

- Student focus is emphasized in most conceptualizations of micro-adaptive teaching in that it highlights that the teacher adjusts to students' individual developmental states, differences, and learning needs (Hardy et al., 2019; Gallagher et al., 2020). In our content-specific approach, this means that the student focus grasps to which extent a teaching practice picks up and includes students' individual ideas and strategies in the sense-making moment.

- Goal focus refers in particular to accompanying or pushing students along the content trajectory towards the learning goal (Chazan \& Ball, 1999). It has been popular in designs and research on macro-adaptivity but is rarely found in the context of micro-adaptivity.

In this conceptualization of micro-adaptivity, the student focus and the goal focus are operationalized independently, but it is the combination of strong student focus and strong goal focus that characterizes teaching practices as adaptive.

\section{Research Questions}

In light of the current state of research and based on the presented conceptualization, we pursue the following research questions in the multiple-case video study:

(RQ1) What teaching practices do teachers use for working with students' ideas and strategies and for bringing them to the content goals?

(RQ2) How can these teaching practices be characterized with respect to their degree of micro-adaptivity?

\section{METHODS}

\section{Research Context of the MESUT Project}

The research questions were pursued in a learning-process study that was part of the larger mixedmethods MESUT project (Erath \& Prediger, 2021). The larger project is investigating various aspects of teaching learning processes in small groups of 3 to 6 students aged 10-13 years old with a teacher. These small groups were organized in an intervention that aimed at fostering students' conceptual understanding of fractions (Prediger et al., 2022). Five main design principles guided the intervention design (Prediger \& Wessel, 2013): 
(DP1) Focus on conceptual understanding. Developing conceptual understanding, in other words, constructing meanings of mathematics concepts and the connections between knowledge elements and strategies (Hiebert \& Carpenter, 1992) is the core aim of the intervention, especially for the part-of-a-whole concept and the comparison of fractions.

(DP2) Maintain high cognitive demands. High cognitive demands are established by rich tasks with demanding cognitive activities, but only maintained by their enactment in the interaction (Henningsen \& Stein, 1997). Especially for underprivileged students, maintaining high cognitive demands is challenging for teachers, but essential for providing equitable learning opportunities (DIME, 2007).

(DP3) Engage students in rich discourse practices. Conceptual understanding and high cognitive demands can best be achieved when students are engaged in rich discourse practices such as arguing and explaining meanings (Moschkovich, 2015), including support for discursively weak students in participating in these practices (Erath et al., 2018).

(DP4) Connect multiple registers and representations. Bruner's (1967) classical design principle of switching between multiple representations (graphical, symbolic, textual, etc.) has been extended to emphasize not only switching but connecting representations explicitly (Prediger \& Wessel, 2013). For students with low academic language proficiency, it has been further extended to explicitly connecting the everyday, academic, and technical register (Clarkson, 2009).

(DP5) Use macro-scaffolding to sequence and combine content and language trajectories. The principle of macro-scaffolding suggests sequencing content and language trajectories starting from students' informal resources to more formal concepts and procedures (Adler, 2001) and from students' everyday language to academic and technical language (Gibbons, 2002). Having already sequenced the learning trajectory in the planning of lessons is a typical act of macroscaffolding, by which support for leveraging students' meaning-making along the content and language trajectory is carefully planned and enacted (Prediger \& Pöhler, 2015).

The teaching intervention spanned over five sessions of 90 minutes each. It was implemented in 49 small groups of 3 to 6 students by novice mathematics teachers. To compensate for their limited teaching experience, the novice teachers were intensively prepared for the intervention in video-based workshops by discussing the content in view as well as micro-adaptive teaching practices for developing students' ideas towards the mathematical and language-related learning goals.

In the larger project context, the intervention in these small groups has been shown to be effective in a cluster-randomized controlled trial with 589 students (Prediger et al., 2022) in which the students in the intervention group had significantly higher learning gains in conceptual understanding of fractions than the students in the control group. This means that on average the teaching was shown to be successful in enhancing students' conceptual understanding. However, because the small groups' learning gains showed major variations in spite of the same teaching material, we started analyzing the teaching practices to illuminate some of the detected differences.

\section{Data Corpus for the Study of Adaptive Teaching Practices}

For the qualitative study of the adaptive teaching practices that is presented in this paper, we selected about 410 minutes of video data from the intervention with small groups (of 3 to 6 students each) taught by novice teachers. The selection was necessary for the tasks and for the groups: 
- The video data focuses the teacher-student interaction during a sequence of four focus tasks in which the comparison of fractions is first explored individually, then students' ideas are collected and systematized (as shown in Figures 1 and 2), as this is the topic in view of this paper.

- Out of all 49 small groups of the larger study, we selected 19 focus groups that were representative of the students' achievement levels, cognitive ability, academic language proficiency, and pre-test scores as assessed by quantitative measures in the larger project (Prediger et al., 2022).

\section{Methods of Data Analysis for Capturing Micro-Adaptivity}

The 410 minutes of video material was transcribed for the qualitative analysis. All transcripts were translated from German to English by the authors and simplified to increase readability while keeping all relevant nuances. Brackets ("[ ]") indicate relevant actions and additions for the readers' understanding, and number signs ("\#") indicate turn taking without pause.

The analytic procedure was operationalized based on the conceptualization of micro-adaptive teaching practices as steering trajectories on a content-specific navigation space (from Figure 3 ). For this operationalization, we depicted teachers' and students' utterances in the content-specific navigation space (and interpreted them as footsteps) and teacher's moves as labeled arrows (and interpreted them as steering). This operationalization allows empirical identification of teaching practices as recurrent patterns of these steering trajectories in the content-specific navigation space and characterization of them according to the student focus and goal focus. More concisely, the qualitative data analysis was analyzed using five analytic steps, some deductive and some inductive:

Step 1: Identifying sense-making moments. In line with Schwarz et al. (2021), sense-making moments were identified in the transcribed video data in the following way: They focus on making sense of concepts or representations, they begin with the initiation of a problem or question (by the teacher or a student) and end when it is marked as being finished in the group's shared discourse. Usually, this extends from 2 to 10 turns, and it is of course not guaranteed that the sense-making opportunity was fruitful for the sense-making of each individual student. In total, 82 sense-making moments were found in the focus video data, occurring in about $70 \%$ of all episodes.

\section{Step 2: Deductive coding for locating chains of utterances in the content-specific navigation space.}

(a) Locating students' and teachers' utterances in the content-specific navigation space is a deductive step of coding: Each utterance was coded by the $\|$ reference object $\|$ and the $\|$ transformation strategy|| that were implicitly or explicitly focused on (see Figure 3). In the analytic texts, the $\|\ldots\|$ symbols are used to mark these deductive codes.

(b) For capturing in how far teachers' and students' utterances align with respect to the representations, each utterance was coded by the representation it addressed (" $\mathrm{s}$ " for symbolic, " $\mathrm{g}$ " for graphical, "c" for contextual). 


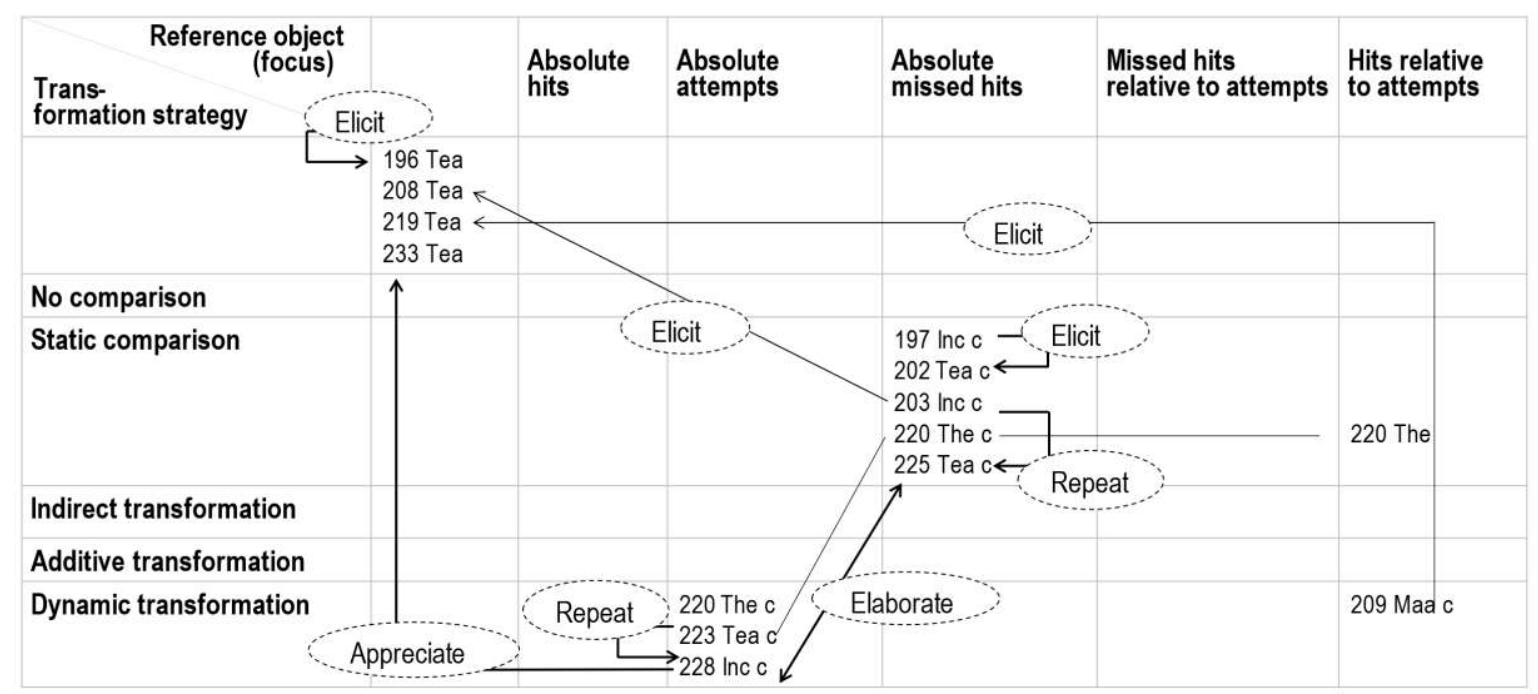

Figure 4. Steering trajectory on the content-specific navigation space (example showing the coded arrows and utterances using the abbreviations "s" for symbolic, "g" for graphical, and "c" for contextual)

(c) Following the pathway analytic procedure outlined in Prediger and Erath (2014), the chain of utterances is depicted geometrically in the content-specific navigation space by successively entering turn number and participant's name in the fields of ||reference object|| in the columns and \|transformation strategy\| in the rows (see Figure 4 for an example). Utterances that do not refer to a specific field are located in an open field at the top left. If speakers are only interrupted by side conversations, several turns of a longer utterance are summarized in order to achieve a better overview.

(d) To mark the pathways, the succeeding fields are connected with arrows (unidirectional arrows symbolize the movement, bidirectional arrows symbolize that two different fields of the contentspecific navigation space are contrasted or compared).

Step 3: Deductive coding of teachers' steering activities by move. After drawing the pathways for the chain of all utterances using fields and arrows, teachers' steering activities are deductively coded by the affiliated teacher move (symbolized by ovals attached to arrows in the figures and marked by -...- in the written analysis). Table 1 presents the definition and delineation of all codes and references to moves in the literature. Additionally, a tentative assignment to strong or weak student focus and strong or weak goal focus is suggested. The multiple entries of "ambiguous" at this point already show why the unit of analysis can often not be the isolated teacher move but the complete sense-making moment.

Step 4: Identifying teaching practices for sense-making moments by inductive categorization. The central step with theory-generating potential is Step 4, in which an inductive categorization of the teachers' steering trajectories is conducted by comparative analysis. In contrast to Schwarz et al. (2021) and Prediger and Erath (2014), some sense-making units were split into several teaching practices (the non-considered part is then marked in grey on the concept map). 
Table 1. Deductive codes for teacher move (all moves are marked by - ...--) and tentative assignment to focus

\begin{tabular}{|c|c|c|c|}
\hline Move & $\begin{array}{l}\text { Definition of the move and delineation from other moves } \\
(\leftarrow \text { and reference to moves in literature in brackets) }\end{array}$ & $\begin{array}{l}\text { Student } \\
\text { focus }\end{array}$ & $\begin{array}{l}\text { Goal } \\
\text { focus }\end{array}$ \\
\hline -Elicit- & $\begin{array}{l}\text { - Initiation moves to bring students' strategies into shared discourse } \\
\text { - Unlike -elaborate- it does not serve to consolidate knowledge } \\
\text { - ( } \leftarrow \text { "exploring what the child has already done," Jacobs \& Empson, 2016; } \\
\text { "questioning," Parsons et al., 2018) }\end{array}$ & strong & ambiguous \\
\hline $\begin{array}{l}\text {-Elabo- } \\
\text { rate- }\end{array}$ & $\begin{array}{l}\text { - Follow-up move to activate students' consolidation of own strategies by generic or specific } \\
\text { questions including teacher support for students (e.g., hint to visual) } \\
\text { - Unlike -initiate student repair-, focus on expanding, not correcting student utterances; } \\
\text { unlike -portion-, limited hints towards the content goals are given } \\
\text { - ( } \leftarrow \text { "activating students to deepen their thinking," Munson, 2019; Smith \& Stein, 2018; } \\
\text { "questioning" and "challenging," Parsons et al., 2018, or } \\
\text { "exploring details of the child's existing strategies," Jacobs \& Empson, 2016) }\end{array}$ & strong & ambiguous \\
\hline $\begin{array}{l}\text {-Appre- } \\
\text { ciate-l } \\
\text {-Reject- }\end{array}$ & $\begin{array}{l}\text { - Evaluation moves to confirm accuracy (often praise) or declare a strategy wrong, but without } \\
\text { explanation of reasons } \\
\text { - }(\leftarrow \text { "evaluating," Munson, 2019; "giving feedback," "assessing," Parsons et al., 2018) } \\
\text { - Unlike -repeat- it includes a clear right or wrong evaluation }\end{array}$ & weak & weak \\
\hline $\begin{array}{l}\text {-Initiate } \\
\text { student } \\
\text { repair- }\end{array}$ & $\begin{array}{l}\text { - Follow-up move to make students reflect and correct their own (partially) incorrect strategies } \\
\text { by generic or specific questions } \\
\text { - Unlike -elaborate- the aim is not to deepen a student's strategy } \\
\text { - }(\leftarrow \text { "repair," Buttlar, 2019; "assessing" and "challenging," Parsons et al., 2018) }\end{array}$ & strong & ambiguol \\
\hline -Portion- & $\begin{array}{l}\text { - Series of closed follow-up questions that aim at getting students to utter the correct answer } \\
\text { by reducing the linguistic and mathematical complexity } \\
\text { - Unlike -elicit-, produces mostly short answers, rarely aligned to student thinking } \\
\text { - }(\leftarrow \text { "funneling," Munson, 2019) }\end{array}$ & ambiguous & strong \\
\hline -Repeat- & $\begin{array}{l}\text { - Teacher utterance with verbatim reproduction of one or more students' utterances } \\
\text { - Unlike -complete- or -reformulate-, mathematics or language not enhanced } \\
\text { - }(\leftarrow \text { "repeat utterances," Prediger \& Pöhler, 2015) }\end{array}$ & strong & weak \\
\hline $\begin{array}{l}\text {-Reformu- } \\
\text { late- }\end{array}$ & $\begin{array}{l}\text { - Teacher utterance taking students' utterances to a higher language level (everyday to aca- } \\
\text { demic) while maintaining students' content, usually includes lexical support } \\
\text { - Unlike -complete- focuses on improving language, not mathematics } \\
\text { - }(\leftarrow \text { "modeling," Parsons et al., 2018; "reformulate," Prediger \& Pöhler, 2015) }\end{array}$ & strong & ambiguous \\
\hline $\begin{array}{l}\text {-Com- } \\
\text { plete- }\end{array}$ & $\begin{array}{l}\text { - Teacher utterance for relating, summing up, abstracting, repairing, explicating, or expanding } \\
\text { students' utterances, bringing in new aspects/strategies themselves } \\
\text { - Unlike -continue and connect-, the teacher brings in new information; unlike -input-, the ut- } \\
\text { terance is (at least implicitly) closely related to students' uttered strategies } \\
\text { - }(\leftarrow \text { "making connections" and "explaining," Parsons et al., 2018) }\end{array}$ & strong & strong \\
\hline $\begin{array}{l}\text {-Continue } \\
\text { and con- } \\
\text { nect- }\end{array}$ & $\begin{array}{l}\text { - Teacher utterance for relating, summing up, abstracting, or explicating what was brought } \\
\text { into shared discourse by students, e.g., to focus on specific aspects } \\
\text { - }(\leftarrow \text { "making connections" and "explaining," Parsons et al., 2018; in some cases to "connect- } \\
\text { ing the child's thinking to symbolic notation," Jacobs \& Empson, 2016) } \\
\text { - Unlike -repeat-, students' utterances are expanded, no verbatim replication }\end{array}$ & strong & ambiguous \\
\hline -Input- & $\begin{array}{l}\text { - Teacher utterance for introducing new strategies; often long utterances at the end of sense- } \\
\text { making moments when teacher pushes towards the goal } \\
\text { - Unlike -complete- it does not explicitly reference to students' uttered strategies } \\
\text { - }(\leftarrow \text { "explaining" and "modeling," Parsons et al., 2018) }\end{array}$ & weak & strong \\
\hline $\begin{array}{l}\text {-Organ- } \\
\text { ize- }\end{array}$ & $\begin{array}{l}\text { - Teacher utterance related to disciplinary issues or moving to the next task } \\
\text { - }(\leftarrow \text { "managing," Parsons et al., 2018) } \\
\text { - not directly related to the steering trajectories in the content-specific navigation space but } \\
\text { included for completeness }\end{array}$ & - & - \\
\hline
\end{tabular}


Between the identified teaching practices, the number of applied moves and arrows can differ, as some practices are characterized by only typical arrow and move, while others may contain several. The practices are characterized by typical changes in navigation across the content-specific navigation space or a characteristic change of used moves or both. An adaptive teaching practice is gained as a recurrent pattern of the teacher's steering of the interaction; these patterns derive from specific sequencing and combinations of arrow directions and moves that occur across groups.

Step 5: Characterizing teaching practices with respect to degree of micro-adaptivity. In order to characterize the degree of micro-adaptivity of the teaching practices identified in Step 4, they are ordered according to their student focus and goal focus, taking into account how the teacher works with students' ideas and strategies and how the steering trajectories lead to the intended learning goal of content-specific knowledge construction:

(a) The extent of student focus is characterized by the coded moves and the question of whether teachers' utterances refer to the same field as student utterances (starting points of the arrows).

(b) The goal focus by the direction of arrows: For instance, a steering across the content-specific navigation space to fields down, right, or both down and right indicate an intended increase of mathematical sophistication (often interpretable as indicator for a strong goal focus), while a steering upward can indicate the opposite but is still sometimes useful for going back to students' thinking. Note that a strong goal focus must not be confounded with characterizing if the teaching practice succeeds in developing the intended conceptual understanding.

(c) Those teaching practices that are characterized as having a strong student focus and a strong goal focus at the same time are those that can count as being most adaptive (see Figure 5).

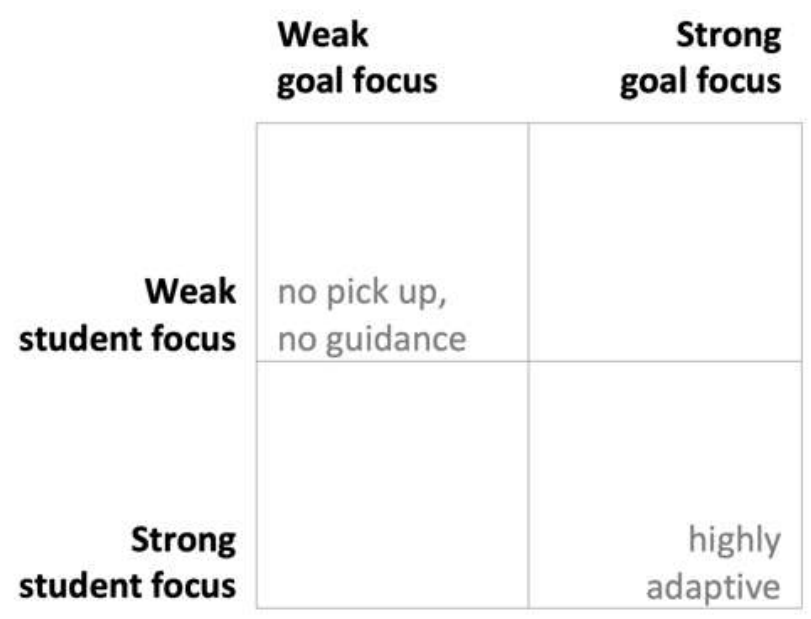

Figure 5. Four-field array for characterizing teaching practices with respect to degree of micro-adaptivity 


\section{RESULTS AND DISCUSSION: EMPIRICAL INSIGHTS INTO CONTENT- SPECIFIC MICRO-ADAPTIVE TEACHING PRACTICES}

The comparative analysis of 82 sense-making moments resulted in the identification of nine recurrent teaching practices that can be characterized with respect to micro-adaptivity according to the degrees of their student focus and their goal focus. In the succeeding subsections, we present the eight practices using a typical steering trajectory in the content-specific navigation space and identify the relevant teacher moves within the pathway, with one ninth being presented as being composed of two others. The first three practices are analyzed in more detail with accompanying transcripts. The last subsection then compares the nine teaching practices with respect to the degree of student and goal focus (Figure 16 can be also read as an advance organizer).

\section{Push Forward: A Teaching Practice with Strong Student Focus and Strong Goal Focus}

The first sense-making moment stems from the beginning of a systematization phase, when the strategy of considering the ||hits relative to attempts\| (from Figure 2) was already established. The students are now called to visualize the scores in the fraction bars (Figure 6), which means connecting the verbally given context situation to the graphical representations (with the later intention to go to \|comparison strategies\| and later ||dynamic transformation strategies $\|$ ).

\section{Transcript 1}

\begin{tabular}{|c|c|}
\hline $\begin{array}{l}59 \text { Teacher } \\
60 \text { Elif }\end{array}$ & $\begin{array}{l}\text { Ok, just tell what you have done. Which bar have you chosen? } \\
\text { [raises her hand] Boys. }\end{array}$ \\
\hline 61 Teacher & $\begin{array}{l}\text { For drawing [the bar for] the boys. } \\
\text { This [bar] was already drawn, here [points to the bar board]. }\end{array}$ \\
\hline 62 Filiz & $\begin{array}{l}\text { [gestures vertically from the end of the bar for the boys to } \\
\text { the two other bars] }\end{array}$ \\
\hline 63 Teacher & Ah, Filiz, what are you doing there [gives her a ruler]? \\
\hline 64 Filiz & Girls and \# \\
\hline 65 Elif & \#They are all equally big, eh, equally long \\
\hline 66 Filiz & [uses the ruler for graphical comparison] \\
\hline 67 Sevgi & Yeah, they are all equally long \\
\hline 68 Filiz & They are all equally long \\
\hline 69 Teacher & $\begin{array}{l}\text { All equally long? So, what do you think about this idea, } \\
\text { here? [points to prompting cards] }\end{array}$ \\
\hline
\end{tabular}

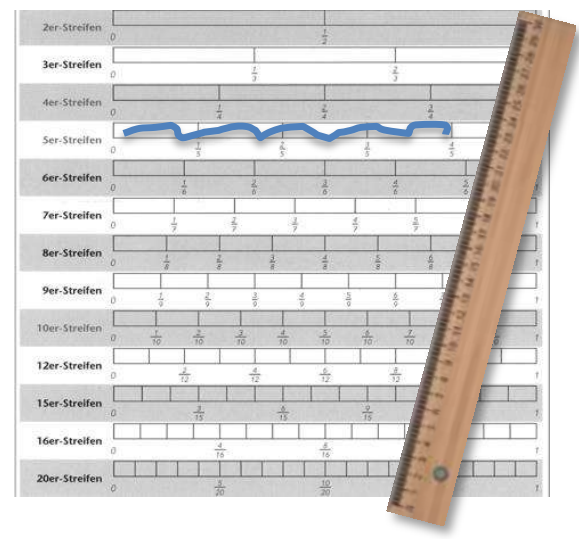

Figure 6. Fraction bar board in Transcript 1

In her introductory question (Turn 59), the teacher -elicits- from the three students how they visualized the scores on the bar board. Her first question addresses \|no comparison\|, but the translation of \|hits relative to attempts\| from the contextual to the graphical representation (c to g); these assigned codes determine the field in the content-specific navigation space in Figure 7. Instead of reporting verbally her ways of visualizing, Filiz gestures vertically up and down to show what she just discovered: A graphical ||static comparison\| of the ||hits relative to attempts\| (Turn 62). In the following, the teacher picks up Filiz's utterance by -elaborating- it further, verbally -eliciting- and manually by giving her a ruler (Turn 63). This steering activity from ||no comparison\| to the \|static comparison\| is depicted by an arrow pointing downwards, especially taking up Filiz's gesture. 
Three students' utterances (in Turn 64-68) refer to the equally long parts of the whole in the bar board and therefore address the ||static comparison\| of the ||hits relative to attempts|| graphically, as intended by the teacher. She -repeats- this observation (Turn 69) and uses the uttered ideas for the next step in steering towards a dynamic comparison (in later turns of the transcript not given here).

\begin{tabular}{|c|c|c|c|c|c|}
\hline $\begin{array}{l}\text { Reference object } \\
\text { (focus) } \\
\text { Trans- } \\
\text { formation strategy }\end{array}$ & $\begin{array}{l}\text { Absolute } \\
\text { hits }\end{array}$ & $\begin{array}{l}\text { Absolute } \\
\text { attempts }\end{array}$ & $\begin{array}{l}\text { Absolute } \\
\text { missed hits }\end{array}$ & $\begin{array}{l}\text { Missed hits } \\
\text { relative to attempts }\end{array}$ & $\begin{array}{l}\text { Hits relative } \\
\text { to attempts }\end{array}$ \\
\hline No comparison & & & 069 Tea & & $059 \mathrm{Teg} \mathrm{gg}$ \\
\hline Static comparison & & & & & $\begin{array}{l}062 \text { Fil g } \\
063 \text { Tea g } \\
065 \text { Elig } \\
067 \text { Sev g } \\
068 \text { Filg } \\
\text { 069 Tea } \longleftarrow\end{array}$ \\
\hline Indirect transformation & & & & & Repeat \\
\hline Additive transformation & & & & & \\
\hline Dynamic transformation & & & & & \\
\hline
\end{tabular}

Figure 7. Teaching practice Push Forward, exemplified by steering trajectory for Transcript 1

This sense-making moment (and its analysis visualized in Figure 7) exemplifies a typical steering pattern that occurred several times across groups, called Push Forward. The practice's characteristic feature is teachers' steering by taking up students' ideas and continuing forward towards the intended learning goal. The move -elaborate- in Turn 63 refers explicitly to an extension of Filiz's idea for the whole group, so the teacher adjusts to Filiz's individual developmental state and learning need (Hardy et al., 2019). The teacher -elicits- ideas and -elaborates- in order to push students' thinking forward along the content trajectory, in this case the arrow points downwards to develop the transformation strategy.

We identified the teaching practice Push Forward in two variants: when students themselves address a more sophisticated strategy that is then taken up by the teachers or when the teachers steer to the next targeted field by expanding students' ideas (as in Transcript 1). Usually, the teaching practice Push Forward relies on the teacher moves -elicit-, -elaborate-, and -complete-. The absolute number of moves and their combination varies (depending on students' reactions), but students must at least be invited to discuss the targeted field.

Push Forward is characterized by a strong student focus, because the strategies stem from the students themselves (as in the transcript) or the students' strategies are leveraged. Looking at the goal focus, two of the three main moves are rated as ambiguous in Table 1. In the context of the teaching practice Push Forward, they serve a strong goal focus since the steering targets towards a lower right field. In total, Push Forward is an adaptive teaching practice used to proceed to the content goals and simultaneously work with students' thinking. 


\section{Contrast Strategies Without Rejecting: A Teaching Practice with Strong Student Focus and Weak Goal Focus}

The sense-making moment serving as an example for the teaching practice Contrast Strategies Without Rejection is taken from a stage of the teaching-learning processes that is later than the one in Transcript 1 , when the small group has already discussed the representation of the visualized shares in the bar board and has come back to the original question of who won the soccer competition (see Figure 2).

\section{Transcript 2}

5 Teacher You said you changed your opinion [nods towards Rahmiye]. Before, you said the girls made it.

6 Rahmiye Yes.

7 Teacher What do you think now?

8 Rahmiye Team of teachers

9 Teacher Now you believe the team of teachers made it. Why?

10 Rahmiye [laughs without speaking]

11 Teacher Yes [calls on Dennis who had raised his hand]

12 Dennis Tie for teachers and girls, because the bars are equally long.

13 Teacher Tie for teachers and girls, OK. Yes, a good argumentation, the bars are equally long. Once again, Rahmiye, your argument, why do you think the teachers had won?

14 Rahmiye Because they, err, 6 , well, because they 16

15 Teacher Uh-huh? [Agreeing]

16 Rahmiye How shall I say that, because they hit 16 times out of 20 .

17 Teacher Uh-huh?

18 Rahmiye But\#

19 Teacher \# there \#

20 Rahmiye \# In the bar, it looks as if this was different, as if it thingy, err

21 Teacher is equal?

22 Rahmiye It is undecided.

23 Teacher Undecided, exactly. There it is important. There are two, err, opinions. Once, you can say the teachers scored most

24 Rahmiye Uh-huh.

25 Teacher Yeah, but perhaps, the teachers were more people, yes. And you are right, actually, it is undecided.

26 Rahmiye Yeah.

At the beginning of the sense-making moment, the teacher -portions- her demand by first asking for a position (Turns 5 and 7). Then she -elicits- an argumentation (Turn 9) from Rahmiye. The questions do not refer to a specific strategy, and Rahmiye's answer does not offer enough information, so Turns 510 are not coded by specific strategies and are thereby assigned to the open field in the content-specific navigation space in Figure 8.

Rahmiye struggles to give reasons for why she thinks the teachers have won (Turn 10). After calling on Dennis (Turn 11), whose answer leads to the \|static comparison\| of \|hits relative to attempts\| (Turn 12), the teacher -elicits- once more an argumentation from Rahmiye (Turn 13).

Rahmiye articulates two different strategies for \|static comparisons $\|$ : In Turn 16, she refers to the contextual representation and argues with \|absolute hits\| (teachers' 16 hits are more than 8 or 4 ) in a contextual representation. In Turn 20 , she refers to the graphical representation that encodes the |hits relative to attempts $\|$ and leads her to say that girls and teachers have a tie. It is not clear whether she adopts the second position from Dennis. The teacher provides lexical support for -reformulating- (Turn 21), which Rahmiye does not take up but prefers to use "undecided" ("unentschieden," a technical term 
in German sports language).

With her longer utterances in Turns 23 and 25, the teacher picks up the strategy expressed by Rahmiye and -continues and connects-. She seizes both of Rahmiye's strategies ("there are two opinions") to compare the teams, (1) by referring to the \|absolute hits|| in the contextual representation and (2) by comparing the ||hits relative to attempts || in the graphical representation. As indicated by the bidirectional arrows, the steering refers to both fields that were previously addressed by Rahmiye with the teacher, -continuing and connecting- her strategies. However, the teacher neither evaluates one strategy as better than the other one nor refuses one, so her steering trajectory does not point towards the intended learning goal in the content-specific navigation space.

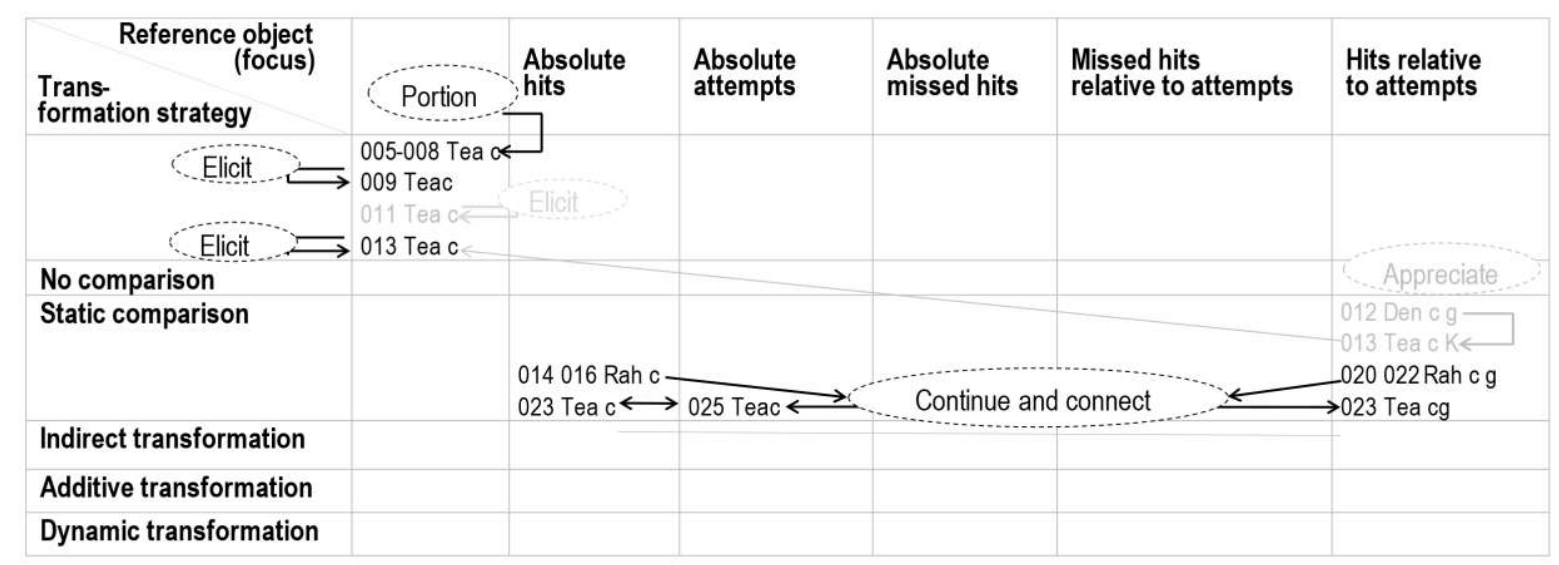

Figure 8. Teaching practice Contrast Strategies Without Rejecting, exemplified for Transcript 2

The presented steering trajectory (and its visualized analysis in Figure 8) offers typical features of the teaching practice Contrast Strategies Without Rejecting as also found in other sense-making moments. The bidirectional arrow links two (or more) fields, which means that they are both integrated in the shared discourse. However, there is no explicit rejection of the less sophisticated idea (neither by the teacher nor another student), even though this would be necessary for pushing towards the content goal. The identified move -continue and connect- for the steering activity from Rahmiye's Turn 20 to the teacher's utterances in Turns 23 and 25 shows an uptake of her ideas (which must be -elicited- first) but without rejection. A rejection or contrast would lead to an attachment of moves such as -initiate student repair- or -elaborate- to the bidirectional arrow (see practice Contrast Strategies In Order To Initiate Productive Struggle) or the teacher move -reject-.

It is evident that the teachers' steering is highly responsive to students' articulated strategies, which is also expressed by the moves -repeat-, -reformulate-, and -continue and connect-. This indicates that this practice has a strong student focus. However, it has only a weak goal focus: Even though one of the linked fields is further right in the content-specific navigation space, the teaching practice misses the opportunity to discuss why one of the strategies is less adequate, so no clear steering towards the content goals is found (at least in this sense-making moment; it might be done at a later stage in the learning process). Thus, in this case, the moves with ambiguous goal focus contribute to a practice with overall low goal focus. 


\section{Take Over and Do It Yourself: A Teaching Practice with Strong Goal Focus and Weak Student Focus}

A typical example for the teaching practice Take Over and Do It Yourself is given in Transcript 3, extracted from the beginning of the systematization phase (same task as in Transcript 1; see Figure 7).

\section{Transcript 3}

161 Teacher Sabine, you have drawn the girls [score on the bar board]

162 Sabine Yes, err, they have shot 10 times and hit 8 of them. And-yeah. If they had hit 10 times, it [points to the shaded part of the fraction bar] would be till there [points to 10/10]

163 Teacher Yes, \#correct

164 Sabine \# Wow

165 Teacher And, err, the have scored, though, \# times 2, virtually

166 Sabine \#Yes

167 Teacher Five times two is ten. Four times two is eight.

168 Sabine Uh-huh, yes.

169 Teacher That means, we have virtually, turned one attempts into two attempts. Then they have to hit the double. Then, the teachers, Marlen.

After -eliciting- Sabine's ideas for connecting the contextual and graphical representation of the ||hits relative to attempts\| with ||no comparison\|, the teacher takes over (Turn 165). He -appreciatesSabine's utterance and gives a new -input- by explaining the \|dynamic transformation\| process in symbolic and contextual representation, although Sabine has not referred to any \|static comparison\| or even \|dynamic transformation\| before (she was not asked). The teachers' explanation of how to refine one into two hits by a symbolic operation addresses the bottom right in Figure 9, hence an arrow indicates the teachers' Do It Yourself jump with the move -input- downwards from ||no comparison\| to ||dynamic transformation\|. Afterwards, the teacher -elicits-Marlen's strategy in the same field that he -elicited-from Sabine before, thus the arrow points upward again to \|no comparison\| of the ||hits relative to attempts\|.

The steering trajectory of Transcript 3 in Figure 9 illustrates the characteristics of the teaching practice Take Over and Do It Yourself: The teacher introduces one or more new strategies that were not addressed before in shared discourse. The practice Take Over and Do It Yourself has a strong goal focus as the steering leads to a more sophisticated field in the content-specific navigation space. But the teacher does not work with students' ideas and shuts down their opportunities to explore these strategies themselves (here the \|static comparison\| and \|dynamic transformation||), so the student focus is weak.

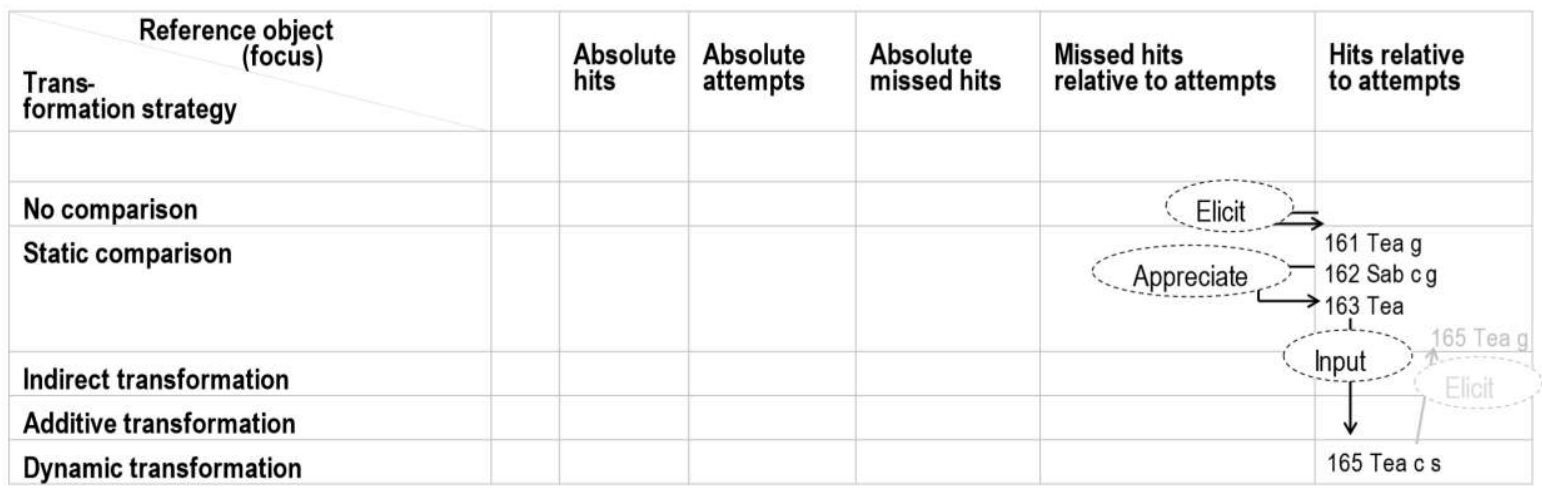

Figure 9. Teaching practice Take Over and Do It Yourself, exemplified by steering trajectory for Transcript 3 
It is interesting to contrast the steering trajectories in Figures 7 and 9 to illustrate how differently the interaction can take place. In Transcripts 1 and 3, both groups' shared discourse starts in the same field and teachers' steering trajectories both lead towards the content goals. But the teachers' moves illustrate that students are pushed forward by working with their own ideas further in Transcript 1, whereas the teacher in Figure 9 incorporates essential ideas himself by -inputs- in Transcript 3.

In other sense-making moments that were also identified as belonging to this teaching practice, the move -input- indicates that teachers do not adapt (or only to a small degree) in order to pick up students' strategies and develop them further. Rather, they take the entire responsibility for the articulated content, which often happens at the end of a longer sense-making episode. The amount of newly introduced ideas varies: Whereas the teacher in Transcript 3 steers two fields further down and uses two different representations, other teachers bring in several of their own ideas. In these cases, the pathway can document arbitrary jumps.

Concerning the student focus, the move that is mainly used, -input- (sometimes -portion-), indicates that teachers base the steering on explaining their own strategies rather than taking up students' strategies and giving them space for making their own contributions and connections. Looking at the goal focus, -input- is characterized as strong in goal orientation as it leads to the teachers' predetermined direction. To sum up, Take Over and Do It Yourself is characterized by a weak student focus and strong goal focus.

\section{Consolidate: A Teaching Practice with Strong Student Focus and Varying Goal Focus}

The teaching practice Consolidate is exemplified without transcript by the steering trajectory of an interaction of Makbule, Kiran, Vehbiya, and their teacher working on the same task as the groups in Transcripts 1 and 3 . The sense-making moment begins when the teacher -elicits- a justification for why the share of the boys' team fits the graphical representation of the \|hits relative to attempts\|.

\begin{tabular}{|c|c|c|c|c|c|}
\hline $\begin{array}{l}\text { Reference object } \\
\text { (focus) } \\
\text { Trans- } \\
\text { formation strategy }\end{array}$ & $\begin{array}{l}\text { Absolute } \\
\text { hits }\end{array}$ & $\begin{array}{l}\text { Absolute } \\
\text { attempts }\end{array}$ & $\begin{array}{l}\text { Absolute } \\
\text { missed hits }\end{array}$ & $\begin{array}{l}\text { Missed hits } \\
\text { relative to attempts }\end{array}$ & $\begin{array}{l}\text { Hits relative } \\
\text { to attempts }\end{array}$ \\
\hline \multicolumn{6}{|l|}{ No comparison } \\
\hline Static comparison & & & & $\begin{array}{l}\text { Elaborate } \\
\text { Elaborate } \\
\text { Elaborate }\end{array}$ & $\begin{array}{l}\text { 005 Tea c g } \\
007 \text { Mak c } \\
008 \text { Tea g } \\
010 \text { Mak c S } \\
\text { 011 Kir s } \\
\text { 012 Tea } \\
\text { 016 Kir c } \\
\text { 017 Tea } \\
\text { 019 Mak c }\end{array}$ \\
\hline \multicolumn{6}{|l|}{ Indirect transformation } \\
\hline \multicolumn{6}{|l|}{ Additive transformation } \\
\hline Dynamic transformation & & & & & \\
\hline
\end{tabular}

Figure 10. Teaching practice Consolidate, exemplified by a steering trajectory (without transcript)

In the following, the interaction of the group stays in this same field with the teacher -elaboratingfurther in order to connect representations, from the contextual representation to the graphical and symbolic representations (more or less explicit) with students' vivid contributions (some short utterances not 
mentioned in the steering trajectory).

All steering trajectories subsumed under the teaching practice Consolidate share the characteristic that the teachers' moves, and steering's refer to the same field. In the exemplary steering trajectory in Figure 10, all students' utterances also refer to the field; this is not the case for all steering trajectories in this teaching practice. The teachers' moves for Consolidating vary: After -eliciting-, possible teacher moves are -elaborate-, -initiate student repair-, -portion-, -repeat-, -reformulate-, -continue and connect-, and -complete-. At the end of a sense-making moment, teachers also -appreciate-. The Consolidation intensity varies as it depends on the number of moves, which again depend on students' reactions.

Overall, the involved moves indicate a strong student focus for the teaching practice Consolidation. In contrast, the degree of the goal focus varies with the field in which it is located. Figure 10 shows a typical example of teachers' focus on an appropriate intermediate goal (frequently identified in other cases); hence, the teaching practice Consolidate is then characterized by strong goal focus. In other cases where the target field is not appropriate, the goal focus is weaker.

\section{Initiate Productive Struggle by Contrasting Strategies: A Teaching Practice with Strong Student and Goal Focus}

The teaching practice Initiate Productive Struggle by Contrasting Strategies is exemplified without transcript by the steering trajectory of a sense-making moment with Inci, Theodor, Maajid, Yasser, and the teacher in a discussion in the early exploration phase before the bar board was introduced.

\begin{tabular}{|c|c|c|c|c|c|c|}
\hline $\begin{array}{l}\text { Reference object } \\
\text { (focus) }\end{array}$ & & $\begin{array}{l}\text { Absolute } \\
\text { hits }\end{array}$ & $\begin{array}{l}\text { Absolute } \\
\text { attempts }\end{array}$ & $\begin{array}{l}\text { Absolute } \\
\text { missed hits }\end{array}$ & $\begin{array}{l}\text { Missed hits } \\
\text { relative to attempts }\end{array}$ & $\begin{array}{l}\text { Hits relative } \\
\text { to attempts }\end{array}$ \\
\hline & $\begin{array}{c}233 \text { Tea } \\
\uparrow\end{array}$ & & & & & \\
\hline \multicolumn{7}{|l|}{ No comparison } \\
\hline Static comparison & & & & $\begin{array}{l}203 \text { Inc } \mathrm{c}- \\
220 \text { The } \mathrm{c} \\
225 \text { Tea c }\end{array}$ & & 220 The \\
\hline \multicolumn{7}{|l|}{ Indirect transformation } \\
\hline \multicolumn{7}{|l|}{ Additive transformation } \\
\hline Dynamic transformation & Apprecia & & $\begin{array}{l}-220 \text { The } c \\
\\
2223 \text { Tea } \mathrm{c} \\
228 \mathrm{Inc} \mathrm{c}\end{array}$ & & & \\
\hline
\end{tabular}

Figure 11. Teaching practice Initiate Productive Struggle by Contrasting Strategies, without transcript

After the teacher has -elicited- strategies from the students, she uses them to Initiate Productive Struggle by Contrasting Strategies. The teacher begins to -repeat- Inci's (and Theodor's) strategy to compare the \|absolute missed hits $\mid$ in contextual representation and Theodor's strategy to transform the ||absolute attempts|| in contextual representation of the one team into the attempts of the other team by repeated doubling (Turns 223 and 225). Within Turn 225, the teacher focuses the small groups' discourse on those two strategies by contrasting: This is depicted in Figure 11 by the bidirectional arrow and the move -elaborate-. For Inci, the teacher intends productive struggle to reject her idea of a \|static comparison\| of the \|absolute missed hits|| in favor of a more sophisticated ||dynamic transformation\| strategy of \|absolute hits\|. At the same time, the \|absolute hits\| are less adequate than the |labsolute missed hits $\|$, thus there is also a steering leftwards, which can provoke a discussion. 
It is typical for all steering trajectories that belong to the teaching practice Initiate Productive Struggle by Contrasting Strategies that they include a bidirectional arrow and either the -elaborate- or -initiate student repair- move. Furthermore, since at least one of the contrasted strategies stems from the students only, they must have been -elicited- before. The images of the steering trajectories contributing to this teaching practice have different geometries in the content-specific navigation space since they mainly depend on the locations of the fields that represent the strategies that are contrasted.

A strong goal focus becomes visible in Figure 11 by an intended steering towards a more sophisticated strategy (the prompt is successful, as Inci's utterance in Turn 228 indicates). Especially in contrast to the teaching practice Contrasting Strategies Without Rejecting in Figure 8, the move -elaborate- enables the teacher to consider the two different strategies to develop one of them further by initiating productive struggle. Here, the students are invited to rethink why their own strategy might be wrong, which is not realized in Contrasting Strategies Without Rejecting. Moreover, the moves indicate a strong student focus: The moves -elaborate- and -initiate student repair- are usually used to activate students to reflect their own strategy to connect it to the content goals.

To sum up, Initiate Productive Struggle by Contrasting Strategies is characterized by a strong student focus and a strong goal focus, it is hence a highly adaptive teaching practice.

\section{Reconsider Strategies: A Teaching Practice with Strong Student Focus and Varying Goal Focus}

The steering trajectory in Figure 12 is used to exemplify the teaching practice Reconsider Strategies. The example refers to the same task as Transcript 1 and 3 and is from the small group of Liane, Thore, Bugra, and their teacher.

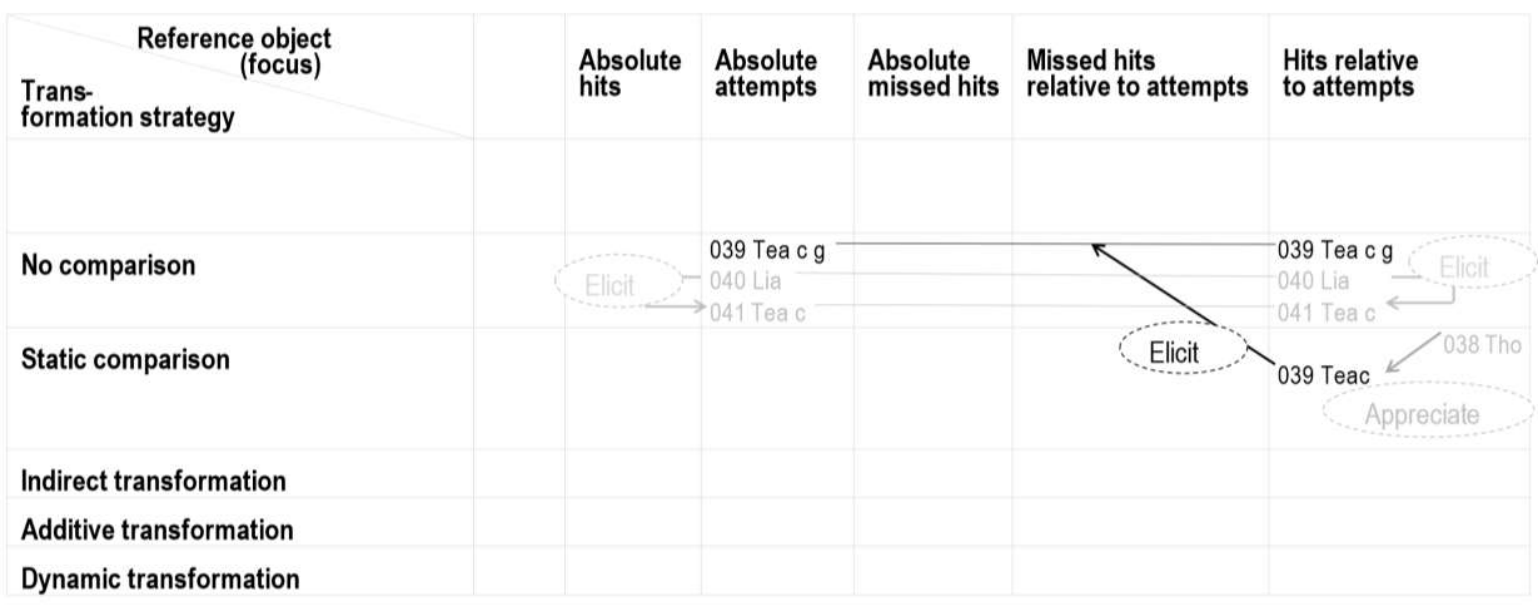

Figure 12. Teaching practice Reconsider Strategies, exemplified by a steering trajectory without transcript

After a short -consolidation- of the \|static comparison\| of the ||hits relative to attempts|| (not shown here), the teacher steers upwards (Turn 39). The small group has not discussed how and why the different representations of ||hits relative to attempts\| and ||absolute attempts|| are related (double coded as the teacher is not explicit enough).

The steering trajectory is typical for the teaching practice Reconsider Strategies, since the interaction is shifted back from an already more sophisticated to a less elaborated strategy (arrow upwards or to the left). Conceivable reasons are diverse and cannot always be analytically separated: Teachers may 
adjust to other students like Liane and Bugra (who might have not yet followed) or intend to repair an expressed, unsustainable structuring by another strategy (without re-entering again).

The teacher moves activated in this teaching practice are usually -elicit- or -initiate student repairand sometimes -portion-. These moves indicate that the student focus is strong. In contrast, the goal focus can vary, as it depends on the targeted field. Although Reconsider Strategies of course means navigating further away from the content goal, it can nevertheless have a strong goal focus when going back was necessary to help all students follow, so it contributes to reaching the goals in the long run. However, sometimes teachers' choices of the addressed field in the content-specific navigation space do not contribute to reaching the goals in the long run, in which case the goal focus is weak.

\section{Pull Out Small Pieces from Student Ideas: A Teaching Practice with Varying Student Focus and Strong Goal Focus}

The next teaching practice is exemplified in Figure 13. The sense-making moment is taken from the ongoing process of systematization, after Jacques, Frode, Jacob, Patrizia, and Lorenz have discussed the representation of visualized shares in the bar board in groups of two or three students each, facilitated by the teacher. Before the teacher uses the teaching practice Pull Out Small Pieces From Students Ideas, he already tried to Consolidate and to Initiate Productive Struggle by Contrasting Strategies in order to adapt to Jacques, who struggles with the ||static comparison\| of the ||hits relative to attempts\|.

Starting with Patrizia's longer utterance in Turn 255, he -portions- information from the students those addresses \|dynamic transformation strategies || of the \|absolute attempts || (Turn 256) and the |labsolute hits|| (Turn 258-262). It is therefore clear that he focuses on an isolated view of the part and the whole first by -portioning- very short statements (less than a whole sentence).

\begin{tabular}{|l|l|l|l|l|}
\hline \multicolumn{1}{|c|}{$\begin{array}{c}\text { Reference object } \\
\text { (focus) } \\
\begin{array}{l}\text { Trans- } \\
\text { formation strategy }\end{array}\end{array}$} & $\begin{array}{l}\text { Absolute } \\
\text { hits }\end{array}$ & $\begin{array}{l}\text { Absolute } \\
\text { attempts }\end{array}$ & $\begin{array}{l}\text { Absolute } \\
\text { missed hits }\end{array}$ & $\begin{array}{l}\text { Missed hits } \\
\text { relative to attempts }\end{array}$ \\
\hline \\
No comparison
\end{tabular}

Figure 13. Teaching practice Pull Out Small Pieces From Student Ideas, exemplified without transcript

In the following the teacher tries to -complete- these small pieces of information himself to end this sense-making moment, which is shown by the arrow pointing towards the bottom right field. But he is interrupted by Jacques who also wants to contribute to the ||hits relative to attempts\| (even though he was not invited).

The steering trajectory in Figure 13 illustrates the characteristics of the teaching practice Pull Out Small Pieces From Student Ideas (Turns 256-264): -Portioning- by posing a series of closed questions that result in little involvement of the students in shared discourse that follows a teacher guided direction, 
which is at best (and at most of the time) directed towards students' next development state (similar to funneling; Munson, 2019). Hence, the goal focus is strong. At the same time the teaching practice has a varying student focus because little information is brought in from the students. The advancement constructed by teachers often favors proceeding to the content goals over maintaining students' needs. But we also identified other sense-making moments when small pieces of information are the most that weaker students can contribute or they are even intended by the task design (comparing shares, for example). So according to our conceptualization, the student focus is in between weak and strong.

\section{Open Questioning: A Teaching Practice with Strong Student Focus and Varying Goal Focus}

We have identified teachers' Open Questioning in almost all of the small groups in the phase of exploration. Figure 14 shows a typical example taken from the small group of Carlotta, Inga, Mattheo, Taleka, and their teacher.

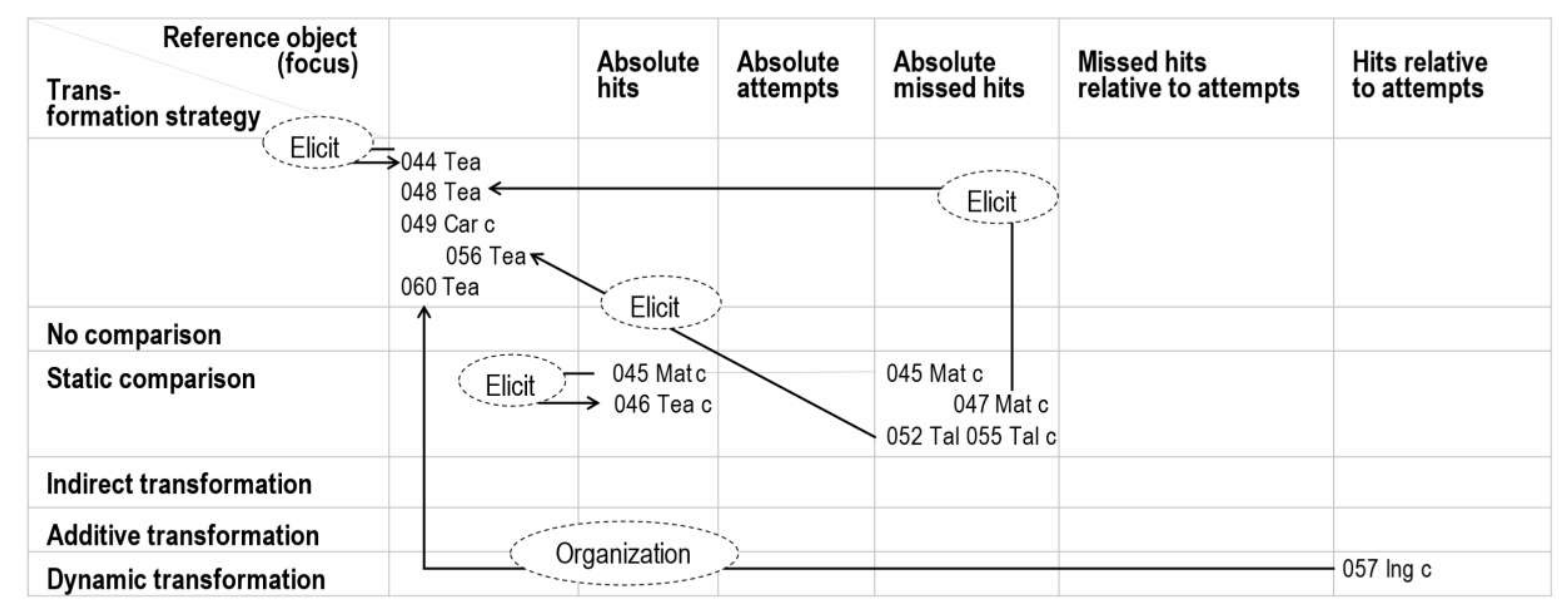

Figure 14. Teaching practice Open Questioning, exemplified without transcript

The teacher -elicits- from the students at first which team has won the soccer context problem (Turn 44), which is assigned to the open field on top left. The students utter manifold ideas that correspond to absolute and relative reference objects as well as to static and dynamic transformation strategies. The arrows indicate that after each of the utterances there is a steering back to the open field combined with -eliciting- another students' idea without the teacher commenting on the uttered strategies.

All pathways that belong to Open Questioning are closely connected to an -elicitation- of students' ideas in all stages of the learning process. The moves attached to the arrows show that teachers do not react explicitly or at all to the uttered strategies as they -repeat, -elicit-, use the move -organize-, or sometimes -appreciate- (indicates teachers' praise that something has been uttered at all). Assessing Open Questioning in terms of goal focus is closely related to the stage of the learning process: In the phase of exploration, a strong goal focus is not necessarily intended because teachers have to elicit students' ideas first to build up on them; therefore, the goal focus cannot be assessed. In other phases, the goal focus is weak because teachers' steering towards the goals is expected, and, if this is not provided, the teachers miss opportunities to proceed in the learning process. The student focus is strong, because students' strategies are brought into shared discourse to advance thinking based on these strategies. To sum up, Open Questioning is characterized by strong student focus and varying goal focus. 


\section{Reconsider and Re-Enter: Combined Teaching Practice}

Besides the eight different teaching practices that have been identified, an often occurring ninth teaching practice, Reconsider and Re-Enter, was found to be composed of two others. The depicted pathway in Figure 15 visualizes that this teaching practice is composed of two already presented practices, Reconsider and Push Forward that are combined sequentially. We add this practice here as this specific composition reveals a different degree of micro-adaptivity.

All steering trajectories categorized under the teaching practice Reconsider and Re-Enter in this case share a single or multiple steering back to fields to the upper left of the original intended (by repairing-, -portioning-, and -eliciting-). However, these steering trajectories demonstrate once more why it is important to take the interaction of whole sense-making moments into account, rather than the single teacher move, to characterize how teachers work with students' strategies: After the steering backward, the teacher intends a steering forward again (-elicit-, -elaborate-, and -portion-) to the originally intended field to adjust to the student's needs first and to bring her back towards the goal. As a result, this interaction can only be jointly analyzed. Reconsider and Re-Enter is characterized by strong student focus as underpinned by the teacher moves, although they differ in the extent to which a student's idea is taken up and further developed or repaired. Since one essential feature of steering is to Re-Enter towards the original field after steering upwards to the left, there is a strong goal focus when the steering forward is directed to a targeted field.

\begin{tabular}{|c|c|c|c|c|c|}
\hline $\begin{array}{l}\text { Reference object } \\
\text { (focus) }\end{array}$ & $\begin{array}{l}\text { Absolute } \\
\text { hits }\end{array}$ & $\begin{array}{l}\text { Absolute } \\
\text { attempts }\end{array}$ & $\begin{array}{l}\text { Absolute } \\
\text { missed hits }\end{array}$ & $\begin{array}{l}\text { Missed hits } \\
\text { relative to attempts }\end{array}$ & $\begin{array}{l}\text { Hits relative } \\
\text { to attempts }\end{array}$ \\
\hline No comparison & $\begin{array}{l}035 \text { Tea c } \leftarrow \\
036 \text { Agi c } \\
037 \text { Mah c }\end{array}$ & $\begin{array}{l}031 \text { Nad c } \\
\text { Portion } \\
\text { Portion }\end{array}$ & $033 \mathrm{Nad}$ & 028 Tea g & $\begin{array}{l}\text { 028 Tea g } \\
033 \text { Nad g } \\
038 \text { Tea c } \\
\text { 039 Agi c } \\
\text { 040 Tea C. }\end{array}$ \\
\hline Static comparison & & & $\begin{array}{l}\text { student } \\
\text { epair }\end{array}$ & $\begin{array}{l}026 \text { Tea g } \\
027 \text { Glog }\end{array}$ & $\begin{array}{l}\text { air } \\
\text { air.... }\end{array}$ \\
\hline \multicolumn{6}{|l|}{ Indirect transformation } \\
\hline \multicolumn{6}{|l|}{ Additive transformation } \\
\hline Dynamic transformation & 041 Agis & 041 Agis & O41 Agis & & 041 Agis \\
\hline
\end{tabular}

Figure 15. Combined teaching practice Reconsider and Re-Enter, exemplified without transcript

\section{CONCLUSION}

Following the call for further research on micro-adaptivity (Parsons et al., 2018), this paper proposes a content-specific approach to micro-adaptivity by conceptualizing teaching practices as steering trajectories in a content-specific navigation space and micro-adaptivity by the degree of student focus and goal focus. With this conceptualization, a teaching practice is only considered highly adaptive if it works with students' ideas and strategies and at the same time strives towards the learning goal.

In this discussion section, we summarize and relate the identified teaching practices to each other, discuss these findings with respect to the current state of research, and derive future research needs from its methodological limitations. 


\section{Summary of Identified Teaching Practices and Their Adaptivity}

In the qualitative analysis of 81 sense-making moments from 19 small groups working on the comparison of fractions, we identified nine different teaching practices (RQ1) and characterized them by their degree of student and goal focus (RQ2). We refrained from giving frequencies for each of them as the data set is too small for quantifications.

Whereas many teachers move turn out to be of multiple use and degrees of micro-adaptivity (see below), the steering trajectories visualized in the content-specific navigation spaces reveal a first characterization of adaptivity: Pathways in which teachers work with students' ideas are those with continuous successions of arrows: A weak student focus is visible in utterances that are not connected in the contentspecific navigation spaces. Pathways that go towards the bottom or right tend to be those with stronger goal focus. Figure 16 locates the nine different strategies in the four-field array suggested in Figure 5. Teaching strategies marked with " " have varying goal focus or varying student focus and are therefore placed in the middle of this dimension.

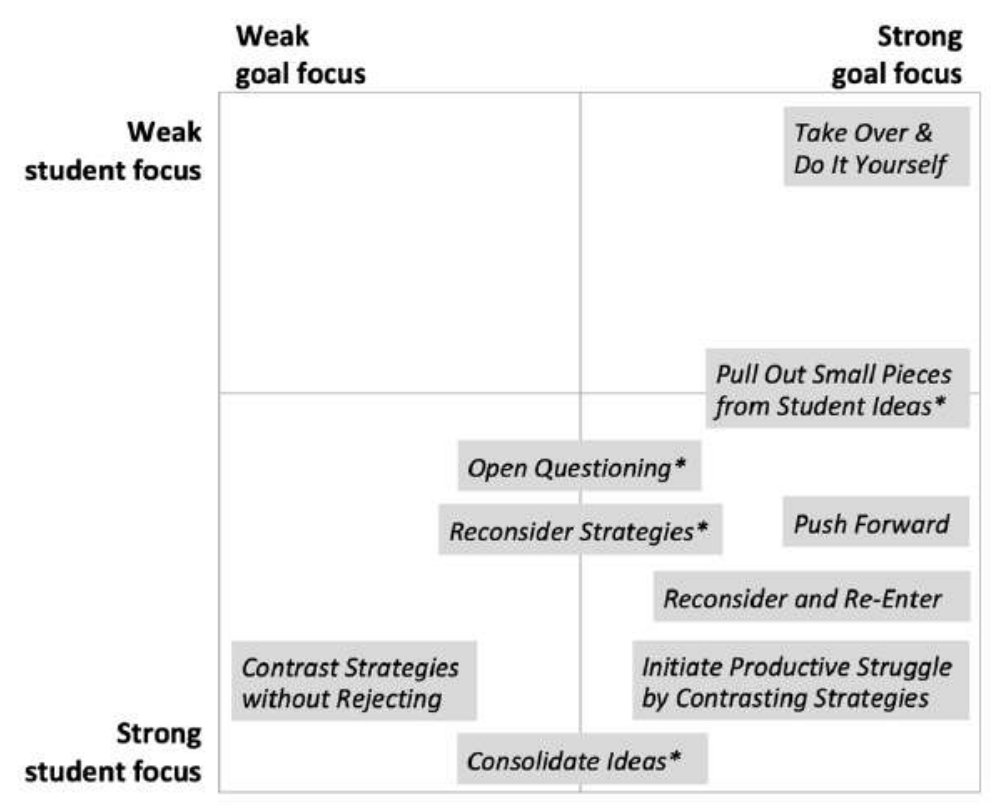

Figure 16. Nine identified teaching practices, characterized in terms of micro-adaptivity by their degree of student focus and goal focus

Regarding the student focus, only one teaching practice (Pull Out Small Pieces From Student Ideas) is in between weak and strong student focus and only one teaching practice (Take Over and Do It Yourself) is characterized as having a weak student focus. Thus, the analyzed teacher-student smallgroup interactions were mainly shaped by at least a medium degree of adaptivity since teachers tried to work with students' ideas.

However, the teaching practices vary strongly with respect to the goal focus, meaning the degree to which they contributed to leveraging students' ideas towards the content goals. One teaching practice was characterized by a weak goal focus (Contrast Strategies Without Rejecting) and three teaching practices have varying goal focus (Consolidate Ideas, Open Questioning, and Reconsider Strategies), which means that whether the underlying steering trajectory can lead to leveraging students' ideas depends on their exact locating in the content-specific navigation space. Those teaching practices that have a strong 
goal focus vary in student focus.

Interestingly, none of the identified strategies has a weak goal focus and a weak student focus at the same time. This means all teaching practices are-to a certain extent-adaptive, but only Initiate Productive Struggle by Contrasting Strategies, Push Forward, and Reconsider and Re-Enter are highly adaptive, as they are characterized by strong goal focus and strong student focus.

When we analyze the identified teaching practices with respect to the activated teacher moves, we see that the same teacher moves can be used for very different purposes. The degree to which a teacher move can contribute to student focus and goal focus can only be captured when the content is sufficiently disentangled and coded in the data analysis. For example, -continue and connect- cannot contribute to the goal focus when activated in the teaching practice Contrast Strategies Without Rejecting but can contribute substantially when activated in the teaching practice Consolidate, as the steering trajectories in Figures 8 and 10 show. -Elaborate- can serve for Initiating Productive Struggle, a practice with strong goal focus, but it can also serve for practices with weaker goal focus. These examples confirm that goal focus in Table 1 can only be tentatively assigned but is never exact without considering the pathways in the content-specific navigation space.

\section{Limitations and Required Future Research}

Of course, the current findings must be interpreted with caution and considered with respect to the specificities and methodological limitations of the study. The focus data corpus consists of 410 minutes of video, transcribed from 19 small groups who all worked on the same tasks and with novice teachers. Although the small-group sample was taken from a larger sample based on the representativeness of students' mathematics achievement, language proficiency, and other control variables, any qualitative study can only cover a small extract of the reality and cannot claim statistical generalizability. Future studies should extend the sample to other small-group data with experienced teachers.

The observation that teachers nearly always succeeded in referring to students' ideas might be traced back to the fact that they worked with only 3-6 students in small groups. As handling whole-class discussions is much more challenging for teachers (Smith \& Stein, 2018), future research should extend also to whole-class discussions.

Most importantly, the currently identified teaching practices are tied to the specific content of fraction comparison and specific content tasks. Although we are convinced that the methodological ap proach of capturing teaching practices by the steering trajectory in a content-specific navigation space can be transferred to other kinds of content-specific navigation spaces, we can expect that future research on other topics will perhaps find further or different teaching practices.

In these future studies, the current operationalization of adaptivity should also be triangulated by analyses of whether the teaching practices characterized as micro-adaptive are actually effective for enhancing students' understanding, because the current conceptualization and operationalization only captures potential effectiveness without empirical evidence for the immediate learning results (Parsons et al., 2018).

\section{Contribution of the Current Study to the State of Research on Adaptivity}

In spite of these limitations, the current study can already contribute to the state of research on adaptivity: Although the general idea of adaptivity is more than 2,000 years old (Corno, 2008), research surveys on adaptive teaching (Hardy et al., 2019; Parsons et al., 2018; Gallager et al., 2020) have identified the research gap between the research on macro-adaptivity, which is often conducted from content-specific 
perspectives, and research on micro-adaptivity, which has mainly been related to generic student aptitudes such as self-regulation (Corno, 2008), cognitive complexity (Nathan \& Kim, 2009), and language proficiency (van de Pol et al., 2010).

This paper suggests a research approach for capturing micro-adaptivity with respect to the intended content learning goals. In line with Schwarz et al. (2021), Huang and Li (2012), and Jacobs and Empson (2016), it focuses on a particular area of mathematical learning content (in our case comparison of fractions) and is related to the intended content trajectories.

Like Jacobs and Empson (2016), our study reveals that the existing general research on teacher moves is highly valuable for the current research but requires their composition in sequences. We adopt a methodological choice similar to Schwarz et al. (2021) to capture not the single teacher move but the sense-making moment spanning several utterances as the unit of analysis. Whereas many studies have characterized micro-adaptivity in terms of a strong student focus, we follow Huang and Li (2012) and Prediger and Pöhler (2015) in also emphasizing the strong goal focus and combine the two systematically. This might be the most crucial contribution of our work to the existing body of conceptualizations, which have focused mainly on one of the two.

The empirical reconstruction of teaching practices with respect to (a) the students' ideas and strategies and their location along the content trajectory/the two-dimensional content-specific navigation space, (b) the applied teacher moves, and (c) the degree of student and goal focus goes beyond the existing empirical findings as it combines more complex perspectives on sense-making moments as larger units. Some of the current teaching practices resonate with strategies found, for example, by Jacobs and Empson (2016) for the modelling cycle, but here for an area of complex mathematical content. Compared to the categories of teacher action listed by Parsons et al. (2018), the identified teacher moves specify teacher responses more precisely.

The identified teaching practices are advocated as important content for teacher professional development. We assume that the better teachers can think about the complete content-specific navigation space in view, the more systematic and deliberate decisions they can take for the steering trajectories to reveal a strong student focus and goal focus at the same time. In particular, the teaching practices $R e-$ consider and Re-Enter, Initiate Productive Struggle by Contrasting Strategies, and Consolidate Ideas deserve attention in professional development to increase micro-adaptivity. This will only be possible when teachers navigate safely in the content-specific navigation space for their topics in view.

\section{Acknowledgments}

The authors thank all the teachers and students involved as well as Lena Wessel for the collaboration in the preceding project MESUT 1 from which we share some data.

\section{Declarations}

Author Contribution

$$
\begin{aligned}
& \text { SP: Conceptualization, fund raising, methodology, writing-original draft, } \\
& \text { writing—review and editing, supervision. } \\
& \text { KQ: Data gathering, formal analysis, writing—original draft, writing- } \\
& \text { review and editing, editing and visualization. } \\
& \text { KE: Conceptualization, fund raising, methodology, writing—original draft, } \\
& \text { writing—review and editing, validation. }
\end{aligned}
$$


Funding Statement $\quad$ : The project MESUT 2 (Developing conceptual understanding by language support: Studying differential conditions of success in the supply-use model) is funded by the German Research Foundation (DFG-grants PR 662/14-2 to S. Prediger and ER 880/1-2 to K. Erath).

Conflict of Interest $\quad$ : The authors declare no conflict of interest.

Additional Information : Additional information is available for this paper.

\section{REFERENCES}

Adler, J. (2001). Teaching mathematics in multilingual classrooms. Kluwer.

Aksu, M. (1997). Student performance in dealing with fractions. Journal of Educational Research, 90(6), 375-380. https://doi.org/10.1080/00220671.1997.10544595

Behr, M. J., Harel, G., Post, T. R., \& Lesh, R. (1992). Rational number, ratio, and proportion. In D. A. Grouws (Ed.), Handbook of Research on Mathematics Teaching and Learning (pp. 296-332). Macmillan.

Behr, M. J., Wachsmuth, I., Post, T. R., \& Lesh, R. (1984). Order and Equivalence of Rational Numbers: A Clinical Teaching Experiment. Journal for Research in Mathematics Education, 15(5), 323-341. https://doi.org/10.2307/748423

Bruner, J. (1967). Toward a theory of instruction. Harvard University Press.

Buttlar, A.-C. (2019). Sequenzielle Analysen interaktiver Verfahren des lehrerseitigen Umgangs mit Schüleräußerungen [Sequential analyses of interactive procedures of teachers' dealing with students' utterances]. In K. Verrière \& L. Schäfer (Eds.), Interaktion im Klassenzimmer (pp. 97-117). Springer.

Chazan, D., \& Ball, D. (1999). Beyond being told not to tell. For the Learning of Mathematics, 19(2), 210. http://www.jstor.org/stable/40248293

Clarke, D. M., \& Roche, A. (2009). Students' fraction comparison strategies as a window into robust understanding and possible pointers for instruction. Educational Studies in Mathematics, 72(1), 127-138. https://doi.org/10.1007/s10649-009-9198-9

Clarkson, P. C. (2009). Mathematics teaching in Australian multilingual classrooms: Developing an approach to the use of classroom languages. In R. Barwell (Ed.), Multilingualism in mathematics classrooms: Global perspectives (pp. 145-160). Multilingual Matters.

Clements, D. H., \& Sarama, J. (2004). Learning Trajectories in Mathematics Education. Mathematical Thinking and Learning, 6(2), 81-89. https://doi.org/10.1207/s15327833mtl0602_1

Confrey, J. (2006). The evolution of design studies as methodology. In K. R. Sawyer (Ed.), The Cambridge Handbook of the Learning Sciences (pp. 135-152). Cambridge University Press.

Corno, L. (2008). On teaching adaptively. Educational Psychologist, 43(3), 161-173. https://doi.org/10.1080/00461520802178466

Corno, L., \& Snow, R. E. (1986). Adapting teaching to individual differences among learners. In M. C. Wittrock (Ed.), Handbook of research on teaching (pp. 605-629). Macmillan. 
DIME - Diversity in Mathematics Education Center for Learning and Teaching (2007). Culture, race, power in mathematics education. In F. Lester (Ed.), Second handbook of research on mathematics teaching and learning (pp. 405-433). Information Age.

Erath, K., \& Prediger, S. (2021). Quality dimensions for activation and participation in language-responsive mathematics classrooms. In N. Planas, M. Schütte, \& C. Morgan (Eds.), Classroom research on mathematics and language - seeing learners and teachers differently (pp. 167-183). Routledge. https://doi.org/10.4324/9780429260889-12

Erath, K., Prediger, S., Quasthoff, U., \& Heller, V. (2018). Discourse competence as important part of academic language proficiency in mathematics classrooms: The case of explaining to learn and learning to explain. Educational Studies in Mathematics, 99(2), 161-179. https://doi.org.10.1007/s10649-018-9830-7

Gallagher, M. A., Parsons, S. A., \& Vaughn, M. (2020). Adaptive teaching in mathematics: a review of the literature. Educational Review, 1-23. https://doi.org.10.1080/00131911.2020.1722065

Gibbons, P. (2002). Scaffolding Language, Scaffolding Learning. Teaching Second Language Learners in the Mainstream Classroom. Heinemann.

Hardy, I., Decristan, J., \& Klieme, E. (2019). Adaptive teaching in research on learning and instruction. Journal for Educational Research Online, 11(2), 169-191. https://doi.org/10.25656/01:18004

Hattie, J. (2009). Visible learning: A synthesis of over 800 meta analyses relating to achievement. Routledge.

Henningsen, M., \& Stein, M. K. (1997). Mathematical tasks and student cognition: classroom-based factors that support and inhibit high-level mathematical thinking and reasoning. Journal for Research in Mathematics Education, 28(5), 524-549. https://doi.org/10.2307/749690

Hiebert, J., \& Carpenter, T. P. (1992). Learning and teaching with understanding. In D. A. Grouws (Eds.), Handbook of research on mathematics teaching and learning (pp. 65-97). Macmillan.

Huang, R., \& Li, Y. (2012). What Matters Most: A Comparison of Expert and Novice Teachers' Noticing of Mathematics Classroom Events. School Science and Mathematics, 112(7), 420-432. https://doi.org.10.1111/j.1949-8594.2012.00161.x

Jacobs, V. R., \& Empson, S. B. (2016). Responding to children's mathematical thinking in the moment: An emerging framework of teaching moves. ZDM - Mathematics Education, 48(1), 185-97. https://doi.org.10.1007/s11858-015-0717-0

Lawrence-Brown, D. (2004). Differentiated Instruction: Inclusive Strategies for standard-based learning that benefit the whole class. American Secondary Education, 32(3), 34-62. http://www.jstor.org/stable/41064522

Lim, W., Lee, J.-E., Tyson, K., Kim, H.-J., \& Kim, J. (2020). An Integral Part of Facilitating Mathematical Discussions: Follow-up Questioning. International Journal of Science and Mathematics Education, 18(2), 377-398. https://doi.org.10.1007/s10763-019-09966-3

Loibl, K., \& Leuders, T. (2019). How to make failure productive: Fostering learning from errors through elaboration prompts. Learning and Instruction, 62, 1-10. https://doi.org.10.1016/j.learninstruc.2019.03.002

Moschkovich, J. (2015). Academic literacy in mathematics for English Learners. The Journal of Mathematical Behavior, 40(A), 43-62. https://doi.org/10.1016/j.jmathb.2015.01.005 
Munson, J. (2019). After Eliciting: Variation in Elementary Mathematics Teachers' Discursive Pathways during Collaborative Problem Solving. The Journal of Mathematical Behavior, 56, 1-18. https://doi.org/10.1016/i.jmathb.2019.100736

Nathan, M., \& Kim, S. (2009). Regulation of Teacher Elicitations in the Mathematics Classroom. Cognition and Instruction, 27(2), 91-120. https://doi.org.10.1080/07370000902797304

Parsons, S. A., Vaughn, M., Scales, R. Q., Gallagher, M. A., Parsons, A. W., Davis, S. D., . . Allen, M. (2018). Teachers' instructional adaptations: A research synthesis. Review of Educational Research, 88(2), 205-242. https://doi.org.10.3102/0034654317743198

Prediger, S., \& Erath, K. (2014). Content or Interaction, or both? Synthesizing two German traditions in a video study on learning to explain in mathematics classroom microcultures. Eurasia Journal of Mathematics, Science \& Technology Education, 10(4), 313-327. https://doi.org.10.12973/eurasia.2014.1085a

Prediger, S., \& Pöhler, B. (2015). The interplay of micro- and macro-scaffolding: an empirical reconstruction for the case of an intervention on percentages. ZDM - Mathematics Education, 47(7), 11791194. https://doi.org.10.1007/s11858-015-0723-2

Prediger, S., \& Wessel, L. (2013). Fostering German language learners' constructions of meanings for fractions - Design and effects of a language- and mathematics-integrated intervention. Mathematics Education Research Journal, 25(3), 435-456. https://doi.org.10.1007/s13394-013-0079-2

Prediger, S., Erath, K., Weinert, H., \& Quabeck, K. (2022, in press). Only for multilingual students at risk? Differential effects of language-responsive mathematics instruction in a cluster-randomized controlled trial on fractions. Journal for Research in Mathematics Education.

Quabeck, K., \& Erath, K. (2020). Individuelle Strukturierungen zur Gleichwertigkeit von Brüchen [Individual conceptions of the equivalence of fractions]. In H.-S. Siller, W. Weigel, \& J. F. Wörler (eds.), Beiträge zum Mathematikunterricht (pp. 733-736). WTM.

Schwarz, C. V., Braaten, M., Haverly, C., \& Xeng de los Santos, E. (2021). Using sense-making moments to understand how elementary teachers' interactions expand, maintain, or shut down sense-making in science. Cognition and Instruction, 39(2), 113-148. https://doi.org.10.1080/07370008. $\underline{2020.1763349}$

Siemon, D., Horne, M., Clements, D., Confrey, J., Maloney, A., Samara, J., Tzur, R., \& Watson, A. (2017). Researching and using learning progressions (trajectories) in mathematics education. In B. Kaur, W. K. Ho, T. L. Toh, \& B. H. Choy (Eds.), Proceedings of the 41st Conference of the International Group for the Psychology of Mathematics Education (Vol. 1, pp. 109-136). Singapore: PME.

Simon, M. A. (1995). Reconstructing mathematics pedagogy from a constructivist perspective. Journal for Research in Mathematics Education, 26(2), 114-145. https://doi.org/10.2307/749205

Smith, M. S., \& Stein, M. K. (2018). Five practices for orchestrating productive mathematics discussions (2nd ed.). NCTM.

van de Pol, J., Volman, M., \& Beishuizen, J. (2010). Scaffolding in Teacher-Student Interaction: A Decade of Research. Educational Psychology Review, 22(3), 271-296. https://doi.org/10.1007/ $\underline{\text { s10648-010-9127-6 }}$ 